\title{
LA DELIMITACIÓN TERRITORIAL ENTRE EL REINO DE MURCIA Y EL REINO DE VALENCIA DURANTE LA EDAD MEDIA: EL AMOJONAMIENTO DEL ESPACIO FRONTERIZO EN EL SIGLO XV ${ }^{1}$
}

\author{
Juan Antonio Barrio Barrio \\ Universidad de Alicante
}

\section{RESUMEN}

La Sentencia arbitral de Torrellas de 1304, no estableció unos límites territoriales precisos entre el reino de Murcia y el reino de Valencia, en torno al río Segura, planteó numerosos conflictos territoriales entre los habitantes que vivían a ambos lados de la frontera, ya que el devenir cotidiano se veía perturbado por las tensiones y conflictos que se suscitaban en torno al aprovechamiento económico en los espacios limítrofes o fronterizos y cuya resolución se trasladaba a las autoridades municipales de Murcia y Orihuela, los municipios más afectados por estas disputas. Esta situación se prolongó desde principios del siglo XIV hasta la segunda mitad del siglo XV, cuando las autoridades locales de dichas ciudades, decidieron acometer la definitiva y precisa delimitación territorial de sus respectivos espacios fronterizos y el correspondiente amojonamiento físico del territorio.

Palabras clave: Frontera Delimitación Mojón Territorio Siglo XV Orihuela Murcia.

1 El artículo se ha elaborado en el marco del proyecto de investigación "Estudio de los límites históricos que separan los municipios de Pilar de la Horadada y San Pedro del Pinatar". 


\section{ABSTRACT}

The imprecise territorial demarcation established for land along the banks of the Segura River between the Kingdom of Murcia and the Kingdom of Valencia, following the Treaty of Torrellas in 1304, led to numerous disputes between inhabitants on either side of the frontier as daily life became disrupted by tension and conflicts over the economic use of borderlands or frontier areas. Disputes were taken to Murcia and Orihuela, the most affected towns, to be resolved. This situation lasted from the early 14th century to the second half of the 15th century, when the local authorities of the two towns decided to carry out a precise and definitive demarcation of their borderlands and set out physical boundaries for their corresponding frontiers.

Keywords: Border Delimitation Cairn Territory XV Century Orihuela Murcia.

\section{LA ORGANIZACIÓN SOCIAL DEL ESPACIO EN LA GOBERNACIÓN DE ORIHUELA. LAS DINÁMICAS POBLACIONALES. SIGLOS XIII-XV}

Las primeras cuestiones que se deben plantear para alcanzar a comprender el poblamiento de la Gobernación de Orihuela, un espacio fronterizo, entre los siglos XIV y XV son sus bases poblacionales históricas y étnicas.

En el sur del reino de Valencia la frontera fue uno de los elementos más característicos en la organización social del espacio. Para el período comprendido entre el siglo XIV y principios del siglo XVI, Orihuela era la ciudad más importante del sur del reino de Valencia y capital de la gobernación general y núcleo articulador de las relaciones políticas con la Corona y eje de los intercambios comerciales dentro de la demarcación, contando con una población fiscal en torno a los 5.000 y 9.000 habitantes respectivamente. El dato demográfico más próximo al periodo objeto de este estudio, es la imposición extraordinaria que con motivo de las bodas de Don Fernando ${ }^{2}$ fue exigida a sus vasallos del término de la villa de Orihuela en 1353. La cantidad asignada para sufragar este tributo ascendía a 20.000 sueldos más un caballo de 1.000 sueldos propiedad de Bonanat Miró. El Consell de Orihuela decidió distribuir el pago del impuesto entre las casas de la villa de Orihuela y su alfoz. Se contabilizaron 1.829 casas, que fueron distribuidas en cinco estamentos fiscales diferentes a tenor del valor de cada casa. De esta forma había 756 casas con valor de 500 sueldos, 363 con valor de entre 500 y 1.000

2 Alfonso IV, el Benigno, contrajo matrimonio en segundas nupcias con Leonor de Castilla, hermana de Alfonso XI, de cuyo matrimonio fue concebido el infante Fernando, hermanastro, por tanto, de Pedro IV. Para complacer a la reina Leonor, Alfonso IV dotó a su hijo Fernando con un extenso patrimonio, que incluía la villa de Orihuela. 
sueldos, 403 casas con valor de entre 1.000 y 4.000 sueldos, 123 con valor de entre 4.000 y 8.000 sueldos y 184 con valor de entre 8.000 y 10.000 sueldos. Aplicando un coeficiente de 4`5 habitantes por casa, tendríamos una población estimada de 8024 habitantes $^{3}$. Estos datos evidentemente siempre tienen que ser estimativos, atendiendo a la movilidad de la población y a los fuertes aumentos y descensos que se debían producir por coyunturas favorables o desfavorables ${ }^{4}$. Para Orihuela disponemos de un dato elocuente. Después de haberse realizado el mencionado censo de casas para aplicar el impuesto extraordinario que se debía abonar al señor de la villa, una nueva exigencia por parte del señor de una contribución extraordinaria en mayor cuantía, provocó el repentino abandono de la localidad de hasta ochenta vecinos, debiendo aplicar el Consell medidas urgentes para evitar un éxodo mayor ${ }^{5}$.

\begin{tabular}{|l|l|r|r|r|c|}
\hline \multicolumn{6}{|c|}{$\begin{array}{c}\text { RIQUEZA IMPONIBLE EN ORIHUELA EN 1353. COMPARATIVA CON LA RIQUEZA IMPONIBLE } \\
\text { DE BASILEA EN 1446 }\end{array}$} \\
\hline $\begin{array}{c}\text { ORIHUELA } \\
(1353)\end{array}$ & \multicolumn{1}{|c|}{$\begin{array}{c}\text { BASILEA } \\
(1446)\end{array}$} & $\begin{array}{c}\text { ORIHUELA } \\
(1353)\end{array}$ & $\begin{array}{c}\text { BASILEA } \\
(1446)\end{array}$ & $\begin{array}{c}\text { ORIHUELA } \\
(1353)\end{array}$ & $\begin{array}{c}\text { BASILEA } \\
(1446)\end{array}$ \\
\hline RIQUEZA (sueldos) & RIQUEZA (Gulden) & \multicolumn{2}{|c|}{ PERSONAS } & \multicolumn{2}{c|}{ PORCENTAJE } \\
\hline Menos de 500 & Menos de 500 & 756 & 2548 & 41,33 & 89,6 \\
\hline $500-1000$ & $500-1000$ & 363 & 128 & 19,85 & 4,67 \\
\hline $1000-4000$ & $1000-4000$ & 403 & 117 & 22,03 & 4,1 \\
\hline $4000-8000$ & $4000-5000$ & 123 & 15 & 6,72 & 0,5 \\
\hline $8000-10000$ & $5000-10000$ & 184 & 23 & 10,06 & 0,8 \\
\hline $10000-20000$ & $10000-20000$ & 0 & 9 & 0 & 0,3 \\
\hline Más de 20000 & Más de 20000 & 0 & 1 & 0 & 0,03 \\
\hline \multicolumn{7}{|c|}{ TOTAL } & 1829 & 2841 & 100 & 100 \\
\hline
\end{tabular}

FUENTE: Basilea. POUNDS, N.J.G. Historia Económica de la Europa Medieval. Barcelona, Crítica, 1987, pág. 324. Orihuela. A(rchivo) M(unicipal) de O(rihuela). Contestador, n. ${ }^{\circ} 9$.

3 BARRIO BARRIO, J.A., "Un repartimiento inédito, el repartimiento de Orihuela de 1330", TORO CEBALlOS, F., RODRÍGUEZ MOLINA, J. (Coord.), VI Estudios de Frontera. Homenaje a Manuel González Jiménez, Jaén, 2006, pp. 79-92. En este trabajo, por un error de imprenta, donde dice "765 casas" debería decir "756 casas". Aprovechamos este trabajo para actualizar el dato.

4 Sobre el proceso de inmigración y la movilidad en el territorio de la gobernación vid. BARRIO BARRIO, J.A., "Inmigración, movilidad y poblamiento urbano en un territorio de frontera. La Gobernación de Orihuela a fines del medievo", Revista d'Història Medieval. Universidad de Valencia, 10 (2000), págs. 199-231.

5 RAMON PONT, A., El Infante don Fernando, señor de Orihuela, en la guerra de los dos Pedros (1356-1363). Memoria de licenciatura, Universidad de Alicante, 1982, f. 48. 
Estos datos en comparativa con los de una destacada ciudad europea, Basilea, colocan a la villa de Orihuela en una posición demográfica relevante, en el contexto de los niveles de población urbana del periodo bajomedieval.

Estas cifras evidencian un crecimiento poblacional decisivo hasta llegar al momento crítico de la guerra de los dos Pedros y el descenso que se percibe en el impuesto del monedaje de 1372 y la lenta pero clara recuperación demográfica y económica de la villa durante todo el siglo XV.

Las cuentas del monedaje para Orihuela del año 1372 son las últimas que hemos podido localizar, ya que en fechas posteriores la inmunidad fiscal otorgada por el Ceremonioso nos ha privado de una fuente de gran valor para la historia de la demografía medieval valenciana ${ }^{6}$.

En la tabla presentamos los datos referidos al cobro del morabatí realizado en la villa, los arrabales y las alquerías del término en 1372 y aparecen desglosados en tres columnas: las de los contribuyentes, que comprende a los vecinos con bienes por valor de 105 sueldos; en la segunda los no contribuyentes, los casados que poseían caballo y los ballesteros de la cofradía de San Ginés todos ellos exentos del tributo ${ }^{7}$; apareciendo en último lugar los excluidos de pagar por tener bienes raíces por valor inferior a los 105 sueldos.

\begin{tabular}{|l|c|c|c|c|}
\hline \multicolumn{1}{|c|}{ COBRO DEL IMPUESTO DEL MONEDAJE EN LA VILLA DE ORIHUELA. ANO 1372} \\
\hline Villa & CONTRIBUYENTES & $\begin{array}{c}\text { NO } \\
\text { CONTRIBUYENTES }\end{array}$ & EXCLUIDOS & TOTAL \\
\hline Arrabales & 534 & 242 & & 822 \\
\hline Lugares & 271 & - & 22 & 293 \\
\hline TOTAL. & 839 & - & 34 & 1115 \\
\hline
\end{tabular}

FUENTE: A.R.V. Maestre Racional, 10866, f. 11r.

Lo que hace un total de 822 fuegos para la villa y arrabales y 293 para los lugares del término. Otro dato demográfico relativo a 1409 con motivo

6 A(rchivo) del R(eino) de V(alencia). Maestre Racional, reg. 10866, 10870, 10871, 10872, 10873, 10874, 10875, 10876, 10877, 10879. Cuentas del morabatí años 1372, $1415,1427,1432,1439,1451,1463,1469,1481,1493$. La consulta de esta documentación nos ha permitido verificar, que tras el pago realizado en 1372 en fechas posteriores Orihuela no volvió a contribuir en concepto de morabatí.

7 De los 242 vecinos de la villa no contribuyentes, 70 eran casados que se comieron sus rocines durante el asedio de la villa en la guerra de los dos Pedros, por lo que se les consideró eximidos, 60 eran ballesteros casados de la Cofradía de San Ginés y los 112 restantes eran casados que poseían caballo. 
del censo fijado para establecer el subsidio concedido por el matrimonio de Martín I arroja para Orihuela una cifra de 1.000 fuegos $^{8}$. Para el período comprendido entre finales del siglo XIV y principios del siglo XV Orihuela contaba con una media de 1.000 fuegos. Aplicando el coeficiente 4' 5 nos lleva a una población según el morabatí de 1372 de 3.699 habitantes en la villa y arrabales y de 1.318 habitantes en los lugares del término y con el censo de 1409 de 4.500 habitantes. Siendo estas cifras inferiores a las de 1.829 casas computadas en 1353.

Para poder entender bien el proceso de colonización de estos espacios periféricos y fronterizos, es necesario dilucidar como se realizó tras la conquista cristiana la repoblación del territorio y la elevada o escasa importancia en dicha demarcación territorial del fenómeno de la migración y la evolución cronológica de la problemática poblacional. Con las decisivas aportaciones de Guinot en Els fundadors del Regne de València, se demuestra que la población que se encontraron los conquistadores cristianos del territorio en el siglo XIII estaba formada por una mayoría musulmana y una minoría hebrea, ya que los mozárabes habían desaparecido por completo y que la mayoría de los pobladores que forjaron la repoblación del reino de Valencia procedía del área catalana9 9 .

Con la conquista y control del reino de Murcia en la segunda mitad del siglo XIII, como en Andalucía las instituciones municipales llegan en una fase avanzada $^{10}$. Hay que recordar, además, que el reino de Murcia y el sur del reino de Valencia, tuvieron un carácter periférico y fronterizo en diferentes momentos de su evolución histórica. Periférico para la cristiandad peninsular, pero también para la propia cristiandad mediterránea-occidental. Se ha considerado a estas áreas "extremas" de la cristiandad en la península, como las más originales. Estas zonas que se veían implicadas en un continuo proceso de avance territorial, generaban un fuerte dinamismo en diferentes ámbitos, inflamadas por un optimismo agresivo y expansionista, cuyas consecuencias más notables se reflejaban en la utilización de tecnologías más avanzadas, verbigracia, el rápido y masivo uso del papel a partir del reinado

8 HINOJOSA MONTALVO, J., "Demografía y poblamiento en Alicante durante la Baja Edad Media: siglos XIII-XV", Estudios de Historia Medieval. Homenaje a Luis Suárez, Universidad de Valladolid. Valladolid, 1991, pág. 277.

9 GUINOT, E., Els fundadors del Regne de València. Repoblament, Antroponímia i llengua a la València medieval. 2 vols. Valencia, 1999.

10 GONZÁlEZ JIMÉNEZ, M., Gobierno Urbano, "Las ciudades andaluzas (siglos XIIIXVI). Actas del VI Coloquio Internacional de Historia Medieval de Andalucía", Málaga. Universidad de Málaga, 1991, pág. 17. 
de Jaime $\mathrm{I}^{11}$. Asimismo este dinamismo fue impulsado por las instituciones municipales, las corporaciones socio-profesionales, la introducción del derecho romano y de la escolástica, los centros de estudios, la eficacia burocrática y cancilleresca ${ }^{12}$, la centralización monárquica, el nacionalismo incipiente ${ }^{13}$, la fortaleza de las lenguas vernáculas y del latín cancilleresco, la aparición de nuevos vocablos para denominar la existencia de nuevas realidades espaciales, como sucedió con la creación del término frontaria ${ }^{14}$, las novedosas técnicas militares, la pujanza de las artes comerciales, etc ${ }^{15}$.

Las fases para explicar el desarrollo cronológico del proceso serían primero la conquista y ocupación castellana del territorio entre 1243-1264, con un débil poblamiento cristiano y el establecimiento de pequeños núcleos militares en las fortalezas y los principales centros urbanos controlando el territorio. A partir de 1265 tras el fracaso de la revuelta mudéjar y hasta 1314 se procede a una ocupación sistemática del territorio, con el reparto de lotes de casas y tierras en diferentes fases que se inician desde el centro de los núcleos urbanos y de sus huertos más cercanos y que de forma radial se va ampliando al resto del espacio urbano hasta agotar las posibilidades de ocupación del espacio, llegando a las tierras más extremas y de peor calidad. En cada localidad se realizó un número variable de repartos. En Orihuela donde se ha conservado y estudiado su libro de repartimiento fueron seis ${ }^{16}$. Este códice que se custodia en la actualidad en la Biblioteca Nacional de Cataluña, comienza en 1265 y termina en 1314. Está compuesto con tapas de madera y unas dimensiones de 420 × $270 \mathrm{cms}$., y consta de ochenta y siete folios en pergamino. Está escrito todo el libro del repartimiento en letra gótica y hasta ahora se ha datado hacia la primera mitad del siglo $\mathrm{XIV}^{17}$.

11 BURNS, R.I., El papel de Xàtiva. Xàtiva, 1999.

12 BARRIO BARRIO, J.A., "Los privilegios reales. Centralización estatal y transmisión de la política real", BARRIO BARRIO, J.A., (Ed.)., Los Cimientos del Estado en la Edad Media. Cancillerías, notariado y privilegios reales en la construcción del Estado en la Edad Media. Alicante, 2004, págs. 119-156.

13 BARRIO BARRIO, J.A., "La formació de la identitat nacional al sur del País Valencià en el segle XV", L'Avenç, vol. 111, Barcelona, 2004, págs. 1749-1751.

14 BARRIO BARRIO, J.A., "Origen, evolución y significado del término «frontaria» en la Península Ibérica", MARTÍNEZ GÁZQUEZ, J.M, CRUZ PALMA, O. FERRERO HERNÁNDEZ, C. (Coord.), Estudios de Latín Medieval Hispánico, Firenze, 2011, págs. 979-988.

15 LE GOFF, J., SCHMITT, J-C., Diccionario razonado del Occidente Medieval, Madrid, 2003, pág. 152.

16 La cronología aproximada del repartimiento de Orihuela es la siguiente. Primera. (1265-1266), segunda (1268-1272?), tercera (?), cuarta (1272-1275), quinta (12881296) y sexta. (1300-1314).

17 TORRES FONTES, J., Repartimiento de Orihuela. Murcia, 1988. 
De los seis repartimientos, incluidos en el libro del repartimiento, el sexto repartimiento adquiere una especial relevancia para el objetivo de nuestro estudio, ya que en el texto manuscrito, entre las columnas doscientos treinta y tres y la doscientos sesenta y uno, hay abundantes referencias a la ocupación espacial realizada entre 1300 y 1314 en la zona sur del reino de Valencia que limitaba con el reino de Murcia. Con el sexto repartimiento se culminaba en principio la ocupación plena del espacio asignado en las tierras del sur del reino de Valencia que quedaban por repartir y correspondían al término municipal de Orihuela.

En la descripción de una de las cuadrillas, aparece una clara mención al topónimo Siete Higueras, recogido expresamente en el documento de delimitación de términos de 1441, de la que nos vamos a ocupar en el siguiente trabajo.

"Aquesta es la quadrella de Rabat axi como talla de les crebades que uan fir el barranc de Alpater e axi como tall ues sol exente per les talayas altes prop les crebades e per les comes de la figera en axi como talla per les talayes altes des Algepçars tro al atalaya pus alta que es aguda e por la loma en sus ues mig dia en tro a la serra sobirana alta de Rabat, axi como les aygues uexen de ues ponent $e$ axi como calla per las uertents de les Contendes que son ja de sus escriptes e per les uertents de Pergamisa e axi colles agues uersen a tres mill CCCC at ${ }^{18}$.

En el sexto repartimiento van a aparecer documentados por primera vez, varios topónimos que hacen referencia al poblamiento de la zona sur de la actual Comunidad Valenciana, como Contendes, Comes de la Figuera, Comes de les Figueres o Rabat que corresponden al Campo de la Horadada y en la actualidad se ubican en el término de Pilar de la Horadada ${ }^{19}$.

- Contendes.

En la cuadrilla 234.

"Aquesta es una quadrella de CC at. Que son (CCXXXIV) al cap de la coma del Pozolo axi como talla por las uertens de Pergamisa en tro a las Contendes e daltre parte axi como talla por la solida de Puigdalues saluan et aquels casales que y son [blanco] entro la dicta solida e entro a les uertentes que son de ues mig dia son at.

Las quales donan a $G$. De Parage en contra de tres cauallerias que auia auer per si e per son trabal de la partiçion e per la mesion que y feu e porque era terra crebantada e malparada.

18 Libre dels Repartiments de les terres entre vehins de la molt Noble y Leal e insigne Ciutat de Oriola. Edición facsímil Alquibla. Centro de Investigación del Bajo Segura. Murcia, 2001, columna 236.

19 FERRER I MALLOL, M. ${ }^{a}$.T., "Toponimia medieval d'Oriola", Miscel.lània d'homenatge a Enric Moreu-Rey, Vol. II. Publicacions de l'Abadia de Montserrat, págs. 195-211. 
Aquesta es una quadrella de terra que nom les Contendes axi como partissessen tome a la torre de Pero Roys de Taualina e ab la serra altra [blanco] ab lo cap del Pug d'albi e del cap del Puyg d'albar a ficta coberta tro a les talaies que [blanco] en cap de Pergamisa. E son mill at. Las quales donan a aquestos de jus escriptos: Muller den Tamarit XXV at. Esteuan, amo de Gotier Roys de Nonpot, $X X V$ at. Muller de Joham Peres de Berbegal XXV at. Lorens de Jaca XXV at. Domingo de Tona XXV at. Fija de Pero Sala XXV at. G. De Liminnana L at. G. Uidal XXV at. Pere de Manresa XXV at. Domingo Ferrer XXV at. Fills de Pere Nanuata XXV at".

En la cuadrilla 236.

"(CCXXXVI) Pero Scerdo de Calant XXV at. Quadrellers G. Bosoldon, G. De Liminnana. Summa IX cauallerias e meia.

Aquesta es la quadrella de Rabat axi como talla de les crebades que uan fir el barranc de Alpater e axi como tall ues sol exente per les talayas altes prop les crebades e per les comes de la figera en axi como talla per les talayes altes des Algepçars tro al atalaya pus alta que es aguda e por la loma en sus ues mig dia en tro a la serra sobirana alta de Rabat, axi como les aygues uexen de ues ponent $e$ axi como calla per las uertents de les Contendes que son ja de sus escriptes e per les uertents de Pergamisa e axi colles agues uersen a tres mill CCCC at".

En la cuadrilla 280.

"Item, la quadrella de les Contetes en que a mill et XXV at".

En la cuadrilla 282

"(CCLXXXII) Primerament, trobaren II $^{a}$ comes que non eran asignades en lo libre, es a saber: la coma que dexende del Albada a tinent del terme d'Orchillo et la coma que dien del Fenollar, que son a un tinent, et afrontant dala una parte ab la talayndona del cabeço de Marcho Nauarro et ab la coma del Pozolo et ab la quadrella de que son quadrelleros Johan Carles et Pere de Liminnana, que es atinent del barranch de Pere de Manresa.

Et a tinent de la coma de Pozolo a terra per partir que son tro a DC at. axi como talla del cap del atalaya del Pozolo et ab lo casal que es entre lataya de puyg dalues et ab la uertent de la trencada de Pergamisa et axi com talla ala talaya rasa de las Contentes".

- Comes de la Figuera, Comes de les Figueres.

En la cuadrilla 236.

"(CCXXXVI) Pero Scerdo de Calant XXV at. Quadrellers G. Bosoldon, G. De Liminnana. Summa IX cauallerias e meia.

Aquesta es la quadrella de Rabat axi como talla de les crebades que uan fir el barranc de Alpater e axi como tall ues sol exente per les talayas altes prop les 
crebades e per les comes de la figera en axi como talla per les talayes altes des Algepçars tro al atalaya pus alta que es aguda e por la loma en sus ues mig dia en tro a la serra sobirana alta de Rabat, axi como les aygues uexen de ues ponent $e$ axi como calla per las uertents de les Contendes que son ja de sus escriptes $e$ per les uertents de Pergamisa e axi colles agues uersen a tres mill CCCC at".

En la cuadrilla 282.

"Otrosi, porquels hereders de don San Peres de Sea es a saber: Estauania Sanches de mannament Pergamisa jusana los dicts partidors et ordinadors auengeren ab Corberan Sanches que o ferme et otorga en uen dela que ages la coma de las figeres et de les oliuers, axi como es a tinent dels tamarises que son en lo barranch et de les uertents que partexen terme ab lo cap de les trencades et ab lo cami que ua a Rabat.

Et el dich Corbaran en nom et en ueu de la dicta Estefania renuncia a tut drit que agesse ab lo dicto terme de pergamisa la dicta donna estefania.

Item, les dites comes que son en Pergamisa a tinent de Estefania Sanches et tot lals que es del terme de Pergamisa la uisana et la sobrana roman a partir.

Item, la coma del Albers de la uasa que es del terme de Pergamisa reman a partir".

- Rabat.

En la cuadrilla 236.

"(CCXXXVI) Pero Scerdo de Calant XXV at. Quadrellers G. Bosoldon, G. De Liminnana. Summa IX cauallerias e meia.

Aquesta es la quadrella de Rabat axi como talla de les crebades que uan fir el barranc de Alpater e axi como tall ues sol exente per les talayas altes prop les crebades e per les comes de la figera en axi como talla per les talayes altes des Algepçars tro al atalaya pus alta que es aguda e por la loma en sus ues mig dia en tro a la serra sobirana alta de Rabat, axi como les aygues uexen de ues ponent $e$ axi como calla per las uertents de les Contendes que son ja de sus escriptes e per les uertents de Pergamisa e axi colles agues uersen a tres mill CCCC at".

En la cuadrilla 242.

"Aquesta es una quadrella de mill at. Que son de la que es en dret Algepçars pus alta et aguda asi como talla por la loma en sus en tro la serra alta de Rabat $e$ de la dicha talaya en tro als Agepçars, e de los Algepçars a ficta cuberta en tro a la serra alta de Rabat, la qual fu partida a aquestos dejus escriptos"20.

20 Todos los textos han sido transcritos a partir de la edición facsímil del libro del repartimiento de Orihuela. Libre dels Repartiments de les terres entre vehins de la molt Noble y Leal e insigne Ciutat de Oriola... 
Hemos documentado un séptimo repartimiento, inédito ${ }^{21}$. El documento que hemos localizado en el Archivo Municipal de Orihuela ha permanecido sorprendentemente inédito hasta el presente, ya que del mismo solo se conocían unos datos escuetos que recogió en el siglo XVI el cronista de Orihuela mosén Bellot.

El hecho de no haber sido incluido en el libro este repartimiento, que debería considerarse como el séptimo repartimiento realizado en 1330, nos lleva a plantear a la vista de esta nueva e inédita documentación, que el códice se compuso entre 1314 y una fecha anterior a 1329. Posiblemente después de 1314 las autoridades locales ordenaron la elaboración de un códice que recogiese en un único volumen todos los repartos de tierras realizados entre 1265 y 1314. El libro de repartimiento, dada la trascendencia jurídica y legal del instrumento, como auténtico registro de la propiedad para todos los oriolanos, adquirió un valor añadido especialmente con los traspasos de propiedad realizados tras el cambio de titularidad regnícola de las tierras de Orihuela entre 1296 y 1304, que se incorporaron en la primera fecha a la Corona de Aragón y en la segunda al reino de Valencia. Compuesto el códice, las anotaciones del repartimiento de 1330 se realizaron en papel originalmente, no sabemos si con intención de componer un nuevo códice o incorporarlo al existente. Lo cierto es que los cuadernos que recogían estos repartos de tierras, tuvieron que quedar sueltos o traspapelados, tras el incendio que sufrió el archivo de Orihuela en la guerra de los dos Pedros. De alguna forma, estos cuadernos se recuperaron y fueron cosidos en algún momento al códice que recogía las actas municipales de los años 1390-139722, en la parte intermedia del mismo. Este hecho ha sido el que ha mantenido hasta la fecha, inéditas estas listas de repartos de tierras, a pesar de que Bellot se había hecho eco de este acontecimiento en sus famosos y muy conocidos Anales de Orihuela ${ }^{23}$. Su inclusión en un acta municipal de fecha muy posterior, hacía muy dificultoso localizar esta documentación, que posiblemente se había dado por perdida, ya que el grueso de la documentación municipal seriada del archivo municipal de Orihuela se inicia a partir del año 1355.

Este nuevo hallazgo nos sitúa en una problemática historiográfica que prestigiosos historiadores españoles como Manuel González Jiménez o Juan Torres Fontes ya abordaron en su momento. Se trata de la tan debatida

21 BARRIO BARRIO, J.A., "Un repartimiento inédito..."

22 A.M.O. Contestador, n. ${ }^{\circ}$ 9, ff. $92 \mathrm{r}-122 \mathrm{v}$.

23 BELLOT, P. Anales de Orihuela (siglos XIV-XVI). 2 vols. Estudio, edición y notas a cargo de Juan TORRES FONTES. Orihuela, 1954-1956. 
cuestión de la crisis del siglo XIV y que en fechas recientes ha tenido una interesante revisión y puesta al día ${ }^{24}$.

En los trabajos realizados por González Jiménez o Torres Fontes y por otros medievalistas españoles, se planteaba una cuestión común, la incongruencia o aparente contradicción de los procesos repobladores que se plantearon en la Península Ibérica en las primeras décadas del siglo XIV, época claramente de crisis y profunda recesión demográfica. Se trataba, por tanto, no de buscar la explicaciones a este fenómeno en las lógicas repobladoras basadas en crecimientos demográficos y desplazamientos poblacionales por esa expansión demográfica a otras zonas con el objetivo de cubrir espacios escasamente poblados o que demandaban la llegada de elevados contingentes poblaciones. No pudiendo utilizar esta justificación, había que responder a partir de otras cuestiones o problemáticas. Lo primero que llamó ya la atención de González Jiménez es la coincidencia del proceso repoblador que estudiaba para la zona de Sevilla en el siglo XIV, con otras zonas "periféricas" de la península como Asturias o el País Vasco ${ }^{25}$, a las que podríamos añadir otras áreas periféricas como Lorca y Orihuela, lo que confirmaría la hipótesis anunciada por González Jiménez en 1975 "De confirmarse este carácter "periférico" estaríamos ante un fenómeno cuyo significado desbordaría el marco puramente regional" 26 .

Sin embargo en otras áreas y ya dentro del marco valenciano en el que debemos ubicar el espacio objeto de nuestro estudio, en el siglo XIV se ha producido un descenso considerable en la concesión de cartas pueblas y suelen corresponder a poblaciones de menor importancia respecto a su tamaño, ya que a juicio de Guinot los grandes alfoces y villas ya estaban ocupados y organizados ${ }^{27}$.

Por otra parte, creo que debemos asignar a los datos de los repartimientos el valor relativo que tienen, en relación a conocer datos de inmigración, dado que sabemos que en el caso de la villa de Orihuela, algunas tierras de cultivo pertenecían y eran laboradas por vecinos de localidades como Murcia y Elche y a la inversa, vecinos de Orihuela disponían de tierras en Murcia

24 BOIS, G., La gran depresión medieval: siglos XIV-XV. El precedente de una crisis sistémica. Valencia, 2001. Aunque de fecha anterior, también es reseñable la puesta al día que se llevó a cabo en la XXI Semana de Estudios Medievales de Estella celebrada en 1994. Europa en los umbrales de la crisis (1250-1350). Pamplona, 1995.

25 GONZÁLEZ JIMÉNEZ, M., La repoblación de la zona de Sevilla durante el siglo XIV. Sevilla. Universidad de Sevilla, 2001 (3. ${ }^{a}$ ed.), págs. 89-90.

26 GONZÁLEZ JIMÉNEZ, M., La repoblación de la zona de Sevilla durante el siglo XIV..., pág. 90.

27 GUINOT, E., Cartas de poblament medievals valencianes. Valencia. Generalitat Valenciana, 1991, pág. 30. 
y en Elche. Así por ejemplo cuando el infante don Fernando como señor de Orihuela pretende cobrar un elevado impuesto extraordinario, el Consell recibe numerosas quejas de terratenientes de Murcia que se oponen a contribuir a dicho donativo. Similar situación se produjo con los vecinos de Elche que poseían tierras en el término de Orihuela ${ }^{28}$. Además y en el caso de este repartimiento resulta imposible conocer el origen de los colonos, ya que las escasas anotaciones que aparecen y que puedan indicar un lugar de procedencia no son de ninguna utilidad, ya que hemos descubierto en algunos de estos casos que eran labradores ya establecidos en el territorio. Así en el reparto de la cuadrilla catorceava, aparecen tres nombres en orden correlativo con el mismo apellido, Peres de Saragoça, lo que nos podía inducir a suponer un posible origen de la capital aragonesa, pero el dato se viene al traste, al comprobar que al lado de cada uno de los tres nombres aparece la indicación "alli on laura", expresando que son tierras que estos tres hermanos ya estaban labrando. Quedan abiertas todas las interpretaciones posibles.

Tras el asentamiento masivo de colonos realizado en las primeras particiones del repartimiento de Orihuela, en la primera mitad del siglo XIV se produjeron una serie de dificultades demográficas sucesivas. Entre 1314 y 1331 los ataques granadinos sobre el territorio, provocaron el primer "éxodo" de mudéjares del territorio.

La impunidad de estos ataques pudo ser uno de los motivos que impulsó al Consell de Orihuela a acometer un intenso proceso de repartimiento de tierras en 1330, en la frontera occidental del territorio de su alfoz, precisamente aquella que era más vulnerable a la entrada de contingentes granadinos. Además de ello, el principal argumento que fue esgrimido por los munícipes oriolanos, era el desajuste que se había producido en el proceso anterior de reparto de tierras, ya que algunos prohombres de la localidad disponían de extensos fundíos, sin poder justificar la titularidad de la propiedad de buena parte de estas tierras. Resulta interesante comprobar como el proceso se inicia con cierta celeridad en el momento de producirse un cambio en la titularidad sobre la jurisdicción de la villa de Orihuela. Evidentemente la muerte de Jaime II en 1327 va a tener cambios considerables sobre la villa de Orihuela. El primer indicio se produce en 1328 con la anulación por parte del monarca Alfonso IV de una importante concesión territorial realizada por su predecesor. Pero lo más trascendente va a ser la concesión de la villa, amén de un extenso señorío, que recibió el infante don Fernando, como hijo del rey, que le otorgaba el título de Marqués de Tortosa y le donaba las ciudades, villas y lugares de Tortosa, Santa $\mathrm{M}^{\mathrm{a}}$ de

28 RAMON PONT, A., El Infante don Fernando, señor de Orihuela... 
Albarracín, Orihuela, Alicante, Callosa, Guardamar con todos sus castillos, fortalezas, etc ${ }^{29}$.

El proceso tuvo, pues, una doble vertiente, ya que se procedió a revisar los títulos de propiedad en aquellas zonas del territorio, afectadas por usurpaciones y concentraciones fraudulentas de propiedad. El resultado de estas pesquisas, permitió, pese a la tenaz resistencia de una parte de la oligarquía, usurpar extensos patrimonios. Uno de ellos mediante privilegio real de Alfonso IV, revocando, a instancias del municipio de Orihuela, un extenso donadío que Jaime II había concedido a Pere de Castellvell en el Campo de Salinas además de los almarjales de Molina para su explotación y disfrute ${ }^{30}$.

Como consecuencia de ello, la segunda y más destacada vertiente de esta acción política, fue la de proceder a iniciativa municipal, al reparto de las tierras usurpadas y otras que obraban en poder del consistorio, como acicate para repoblar y colonizar el territorio más fronterizo y periférico de la villa de Orihuela, pero que lo era también de la Procuración y por extensión de la Corona de Aragón, al mismo tiempo que se legalizaban ocupaciones de tierras individuales que algunos vecinos habían hecho en dicho espacio, poniendo en cultivo tierras yermas.

Podemos incluir este repartimiento en la categoría historiográfica acuñada por González Jiménez de "repoblaciones estratégicas"31, en las que por encima de intereses poblacionales o demográficos, se imponen los militares o defensivos, como sucedía en 1330 en las zonas limítrofes y peor defendidas de la gobernación de Orihuela.

Tras procederse a la expropiación de 1328, que no tuvo que ser la única, un año después a finales del año 1329, se iniciaba el proceso de repartimiento de estas extensas tierras de albar y secano y ubicadas en la frontera del territorio. Es una muestra más del proceso complejo de apropiación y distribución de la tierra en las vertientes fronterizas y especialmente en espacios en los que se han producido en pocos años cambios en la soberanía sobre espacios conquistados. Asimismo mostraba los intereses contrapuestos entre los miembros más poderosos de la oligarquía, que posiblemente al socaire del proceso de las expropiaciones y las confiscaciones realizadas tras la larga guerra mantenida con Castilla entre 1296 y 1304, les había permitido

29 A(rchivo) H(istórico) N(acional). Códice 1368-B. Privilegia per Serenissimos Reges ciuitati Oriole concesa. ff. 81 r-85r. A. M.O. Libro de privilegios. ff. 44r-47r. (1328, 12, 28).

30 A.H.N. Privilegia... f. 80 r-v. A.M.O. Libro de privilegios... f. 80 r-v. $(1328,02,10)$.

31 GONZÁlEZ JIMÉNEZ, M., "Poblamiento de la Baja Andalucía: de la repoblación a la crisis (1250-1350)", Europa en los umbrales de la crisis (1250-1350)", XXI Semana de Estudios Medievales. Estella'94. Pamplona, 1995, págs. 63-86. 
hacerse con amplios predios, sobre los que en ocasiones no podían justificar la legalidad de su propiedad. El privilegio otorgado por doña Leonor, como tutora de su hijo el infante don Fernando señor de Orihuela, confirmando las divisiones y particiones de casas, solares, tierras, etc., realizadas por los jurados de Orihuela, demuestra la contundencia en la actuación de las autoridades locales de Orihuela, las controversias que tuvo que suscitar este repartimiento y el apoyo recibido por los entonces señores de Orihuela al proceso $^{32}$. Destacar asimismo que este séptimo repartimiento como el anterior fue realizado por iniciativa municipal, sin ninguna intervención de las autoridades reales.

Estas tierras posiblemente estaban poco pobladas y por tanto abiertas a la entrada de almogávares granadinos. Este pudo ser uno de los motivos, amén de incentivar la colonización cristiana del territorio, que pudo propiciar esta ambiciosa empresa repobladora iniciada por el Consell de Orihuela en 1329. Asimismo este repartimiento permitió consolidar tierras a pobladores que las habían ocupado ilegalmente y que, por tanto, no podían demostrar su legítima propiedad, ya que la zona central de este séptimo repartimiento coincide con una parte de las tierras que se entregaron en el sexto repartimiento. Se puede considerar, por tanto, ejecutado el séptimo repartimiento dentro del carácter metódico con el que fue realizado todo el repartimiento de Orihuela conocido hasta ahora y estudiado por Torres Fontes que ha destacado que en sus seis fases poblacionales recogidas en el libro y que se extienden desde 1265 a 1314 ofrece como nota de conjunto su regularidad y el hecho de haberse realizado de forma metódica ${ }^{33}$. En esta línea el séptimo repartimiento va a permitir un reajuste en las tierras repartidas previamente, tanto con la legitimación de pequeños lotes de tierras ocupados individualmente, como corregir la usurpación de grandes cantidades de tierras obtenidas de forma espuria por algunos vecinos de Orihuela que tuvieron una participación activa en el sexto repartimiento y se beneficiaron impunemente de ello, ya que todo el sexto repartimiento acometido entre 1300-1314 fue realizado por un número fijo y reducido de partidores, que como ha destacado Torres Fontes, se beneficiaron de esta autoridad exclusiva para realizar autoadjudicaciones personales en lotes que sumaban cantidades muy elevadas de tierras, sumando los dos centenares de tahúllas e incluso las quinientas tahúllas que llegó a adjudicarse Fernando Marrades, además de realizar abundantes dotaciones a hijos y familiares, justificados por trabajos realizados por éstos en el reparti-

32 A.H.N. Privilegia... f. 93 r-v. A.M.O. Libro de privilegios... f. 52 r-v. (1332, 05, 01).

33 TORRES FONTES, J., Repartimiento de Orihuela..., pág. CXXXIX. 
miento, como el sogueamiento o la distribución de tierras ${ }^{34}$. Además creemos que las autoridades locales pretendían con el séptimo repartimiento realizar una consolidación poblacional de un espacio peligroso. por encontrarse en uno de los espacios fronterizos y vía de entrada de almogávares granadinos en el territorio. El séptimo repartimiento también fue realizado a iniciativa del Consell de Orihuela, bajo el control y supervisión de los jurados con un número fijo de partidores, que fueron Felip Togores, Sancho Sánchez de Exea, Pere Masquefa y Francesc Martí y con la colaboración como sogueador de Jaume Rocamora.

La falta de documentación nos impide acotar con absoluta precisión el momento final de este largo proceso de repartimiento. En todo caso y como ha manifestado María Teresa Ferrer i Mallol, los setenta años documentados de repartimientos en Orihuela, convierte a este proceso colonizador en el más dilatado en el tiempo de los conocidos para la Corona de Aragón ${ }^{35}$.

La documentación sobre el séptimo repartimiento de Orihuela se inicia el 27 de diciembre de 1329 en casa del jurado Berthomeu Bargallo con los partidores Felip Togores, Sancho Sánchez de Exea, Pere Masquefa y Francesc Martí, que asignaron a los jurados Alfonso Rosell y a Bertomeu Bargallo una caballería de cuarenta tahúllas en la cañada que estaba sobre la torre de Benferri, en el territorio que estaba labrando y roturando Bernat Alio, vecino de dicho lugar. Es interesante constatar la relación que pueda existir entre el apellido Exea que aparece documentado en el séptimo repartimiento en el nombre del partidor Sancho Sánchez de Exea y la importancia que han tenido apellidos como Gea, o De Gea en la zona de Pilar de la Horadada.

Días después siguió un proceso similar. Reunidos los partidores en casa del jurado Bertomeu Bargalla, se procedió al reparto de algunas caballerías de cuarenta tahúllas concedidas a determinados labradores o prohombres sobre esta zona yerma ubicada junto a la torre de Benferri, lo que suscitó las primeras reacciones contrarias de algunos destacados vecinos como Alfonso Rosell, que alegaba poseer la propiedad de algunas tierras que se pretendían repartir, por lo que en una de las zonas previstas para el repartimiento quedó en suspenso su adjudicación a la espera de aclarar la legítima propiedad alegada por algunos prohombres de Orihuela.

Un nuevo lote individual fue concedido al partidor Francesc Martí en la cañada del Garrano. Estas primeras donaciones de tierras consistieron

34 TORRES FONTES, J., Repartimiento de Orihuela... pág. CXXXV.

35 FERRER I MALLOL, M. ${ }^{a}$ T., "Repartiments de terres a Oriola després de la conquesta de Jaume II", Acta historica et archaeologica Medievalia, 22, vol. 2. Homenatge al Dr. Manuel Riu i Riu. Barcelona. Universidad de Barcelona, 1999-2001, págs. 509-535. 
en unas caballerías que se entregaron en primer lugar a algunos partidores y a algunos jurados, antes de iniciar el gran reparto de peonías que se iba a realizar posteriormente.

Tras estos repartos previos que recayeron sobre los partidores, los jurados y el notario del Consell de Orihuela, se procedió al primer repartimiento sistemático de tierras sobre la base de la peonía constituida en veinte tahúllas.

Como ya venía siendo habitual en el resto de Europa occidental, el reparto se realizó de forma sistemática y atendiendo a las prácticas habituales en este tipo de acciones repobladoras, ya que una de las primeras tareas que había que realizar cuando se establecían los nuevos asentamientos agrícolas era la demarcación de los lugares que iban a ocupar las tierras de cultivo ${ }^{36}$. Dado que la zona objeto de reparto ya había sido sometida a repartos de tierras en un repartimiento anterior y esta zona, a diferencia de los espacios totalmente vírgenes y yermos de Europa, ya venía siendo ocupada, al menos, desde época musulmana, las autoridades tenían como principal tarea medir y delimitar adecuadamente cada una de las cuadrillas que iban a ser repartidas.

Para ello y en este repartimiento los jurados se desplazaron a la partida de Benferri en el campo de la matanza, donde realizaron la distribución de los repartos de los lotes de tierras. Para ello utilizaron a un vecino de Orihuela, Jaume Rocamora ${ }^{37}$, como sogueador de las tierras, a la vez que vecinos de la villa instalados en esta zona periférica acompañaron a las autoridades y al sogueador en su recorrido por la amplia zona de tierra que iba a ser medida y objeto de repartos, lo que le sirvió para obtener lotes adicionales de tierra como recompensa por los servicios prestados al municipio. A diferencia de lo que sucedió en fechas similares en el repartimiento de Lorca, donde se sirvieron los repartidores de hasta cuatro clases de medidas más las subdivisiones de cada una de ellas ${ }^{38}$, en Orihuela fue utilizada una única medida de superficie. La medida de superficie utilizada en el siglo XIV para proceder al reparto de tierras, tiene la misma denominación que la que se ha venido utilizando secularmente en la agricultura del sur de la actual Comu-

36 BARLETT, R., La formación de Europa. Conquista, colonización y cambio cultural, 950-1350. Valencia-Granada. Universidad de Valencia-Universidad de Granada, 2003, pág. 190.

37 El linaje Rocamora, fue uno de los más poderosos en la ciudad de Orihuela en el siglo XV. En un trabajo hemos analizado el ascenso social de la familia a través del servicio político de la Monarquía. BARRIO BARRIO, J.A., "Los procuradores del brazo real en las cortes medievales del Reino de Valencia", Aragón en la Edad Media, XXI (2009), pp. 59-98.

38 TORRES FONTES, J., Repartimiento de Lorca. Murcia, 1994, pág. C. 
nidad Valenciana, es la tahúlla, que equivale actualmente en el Bajo Segura a $1.185 \mathrm{~m}^{2} 39$, extensión que aproximadamente sería similar a la del siglo XIV ${ }^{40}$.

Como sucedía con el sexto repartimiento la documentación tiene datos desordenados y alguna laguna documental, como folios prácticamente en blanco, cuadrillas que han sido consignadas para repartir, pero sin aparecer detallados los nombres de los colonos y las tierras recibidas. Asimismo hay diferencias entre la cantidad de tierra sogueada para una cuadrilla y las tahúllas que finalmente se repartieron. Por tanto hay un dato que equivale a la tierra que fue medida para una cuadrilla y la cantidad de tierra que realmente luego fue repartida. Son datos, por tanto, que debemos anotar por separado ${ }^{41}$.

Aunque no tenemos la fecha del reparto de la primera cuadrilla, posiblemente fue en los primeros días de enero, ya que la segunda cuadrilla quedó organizada el viernes cinco de enero de 1330, mientras que el último día reseñado de la primera e intensa fase del repartimiento es el lunes ocho de enero. Estos primeros trabajos se llevaron a cabo prácticamente en una semana de tiempo de intensa actividad. En estos apenas siete días de trabajo se organizaron entre catorce y quince cuadrillas, se soguearon y delimitaron espacialmente cada una de estas cuadrillas, se designaron diferentes cuadrilleros $^{42}$ para cada una de ellas y se procedió y anotó el correspondiente reparto de peonías y caballerías, repartiéndose un total de 270 peonías y 54 caballerías, que sumaban un total de 7.570 tahúllas, que aproximadamente

39 CANALES MARTÍNEZ, G., JUÁREZ SÁNCHEZ-RUBIO, C., "Nuevos regadíos en el secano del Bajo Segura: El modelo referencial de San Onofre-Torremondo (19531992)", Investigaciones Geográficas. Universidad de Alicante, 12 (1994), pág. 236.

40 En el mes de junio de 1308 se realizó la anexión formal Orihuela, Guardamar, Alicante y Elche al reino de Valencia. Asimismo con este privilegio se producía la recepción de los fueros del reino de Valencia por los que se regía la principal ciudad y capital del reino junto a diez privilegios específicos concedidos por Jaime II a dichas villas, que eran disposiciones que habían sido pactadas previamente por las oligarquías de estas localidades, especialmente por la de Orihuela. Una de las peticiones era la de seguir manteniendo la tahúlla como unidad de medida de la tierra, ya que era la que se venía utilizando desde la dominación castellana y era con la que se había realizado todo el repartimiento de tierras desde la conquista cristiana de estas tierras.

41 Hemos observado un proceso paralelo, en el repartimiento de Lorca realizado entre 1330-1337 ya que supuso el reparto de 127.000 tahúllas y afectó a 607 colonos o herederos, que como en el caso de Orihuela es difícil precisar si eran nuevos pobladores o vecinos que ya poseían tierras en el término TORRES FONTES, J., Repartimiento de Lorca...

42 "Cuadrillero" es la denominación utilizada por los historiadores para referirse a los encargados de realizar el reparto de casas y tierras en los repartimientos. GLICK, TH.F. Paisajes de conquista. Cambio cultural y geográfico en la España medieval. Valencia. Universidad de Valencia, 2007, pág. 171. 
serían 7.214.210 $\mathrm{m}^{2}$. Estas tierras habían sido designadas por las autoridades locales de Orihuela como libres para ser repartidas, recibiendo todos sus beneficiarios la tierra en libre alodio, francas de toda carga y para disponer de dichas tierras libremente y a voluntad de su nuevo dueño.

Tras este intenso proceso de repartimiento las actas guardan silencio hasta el martes 17 de abril de 1330, día en que tuvo lugar una importante reunión del Consell de Orihuela, para deliberar precisamente sobre el reparto de tierras realizado hasta la fecha y sobre todo de poner en orden el proceso del repartimiento de tierras realizado en Benferri hasta el día de la reunión, cuyas actas reflejan el deseo de justificar las acciones emprendidas, revisar lo ejecutado por los jurados y los partidores asignados, así como explicar los motivos que han llevado al Consell a ordenar emprender esta empresa.

La principal tarea que han realizado los jurados y los partidores es reconocer la propiedad de las tierras de dicha partida, en función de lo que estaba recogido en los libros de los repartimientos, así como embargar aquellas tierras cuyos propietarios no pudiesen justificar su propiedad, al no haber quedado recogidas en los libros de repartimiento. Precisamente se habían ocupado grandes cantidades de tierras de forma ilegal, por lo que había que proceder al embargo de dichas tierras por parte del municipio.

Por ello el Consell renovaba en esta reunión y ratificaba la orden que ya había dado, para que los jurados y partidores revisasen todas las particiones realizadas y todas las tierras repartidas por cada una de las cuadrillas, para verificar la propiedad de las tierras en dicho lugar, atendiendo a lo que aparecía consignado en los libros de los repartimientos o en las cartas que los dueños pudiesen presentar para justificar su propiedad. Una referencia al final del acta justifica la convocatoria pública de la reunión, ya que el día anterior se habían producido protestas, posiblemente significativas ante Domingo Freixa, lugarteniente de Andreu Masquefa. El Consell manifestaba que no se podían aceptar dichas protestas, ya que había realizado la convocatoria de la reunión mediante pregón público y llamada a reunión del Consell y de todo el pueblo. Esto último también explica la peculiar modalidad de la reunión, ya que a pesar de disponer de ordenanza regia que permitía la convocatoria de Consell General cerrado formado por cuarenta consellers, esta reunión se realizó con convocatoria pública a todos los prohombres de la villa, representando de esta forma la autoridad plena de la Universitas, que refrendaba la actuación que meses antes había emprendido el consistorio oriolano. La reunión se celebró además en un lugar público y cargado de simbolismo, en el porche de la denominada plaza de la Cort de San Salvador. 
Tras esta primera fase intensa y de corta duración en el tiempo y después de haberse celebrado esta trascendental reunión, se reanudaron las tareas de reparto de tierras en la misma zona prevista desde finales de 1329 por las autoridades locales para realizar una importante asignación de tierras y de la propiedad de la misma entre un amplio número de colonos oriolanos.

Pocos días después, el veinte de abril de 1330 se reemprendían las tareas de reparto de tierras, que de nuevo se centraban en la zona de Benferri en el campo de la matanza, con unos primeros lotes sueltos de caballerías y peonías repartidos por los jurados y los repartidores. De nuevo aparecen repartos de tierras sobre lotes ya asignados y recibidos en anteriores repartos por sus dueños, como así consta en una entrada del día veinte de abril de dicho año, cuando los jurados y partidores concedieron a Guillen Morelles 40 tahúllas "que li foren en temps pasat asignades", que confrontan de una parte con el camino que va a Abanilla, de otra con senda que va a los negros y de otra parte con senda sobre el campo de la matanza y de otra con tierra perteneciente al Consell y pendiente de repartir ${ }^{43}$. En el sexto repartimiento Guillen Morelles, actúo como cuadrillero, sin que conste que recibiera en ese momento ningún lote, aunque todo índica que debió recibir tierras por su tarea como cuadrillero, por lo que por error pudo no quedar consignado este reparto en el libro del repartimiento y unos años después el interesado desea que conste expresamente su propiedad en este séptimo repartimiento.

Tras el reparto de estos nuevos lotes de tierras, algunos de importancia como las más de dos mil tahúllas repartidas el primer día de mayo, sucedió el 2 de mayo una importante reunión del Consell, en la que se adoptaron medidas idénticas a las acordadas en la referida reunión del día diecisiete de abril. Reunidos los jurados y partidores acordaron dar validez a los últimos repartos, realizados todos ellos por mandato del Consell de Orihuela y proceder a repartir nuevos pequeños lotes de tierras, posiblemente a vecinos que alegaban no haber sido agraciados en ninguno de los repartos anteriores y disponer de los correspondientes derechos para recibir el lote de tierra requerido $^{44}$. De esta forma se procedía a repartir estos pequeños lotes incluidos dentro de cuadrillas que ya se habían adjudicado.

Esta reunión ponía prácticamente fin al proceso repartidor, quedando por resolver ya en su tramo final estos pequeños desajustes y errores u omisiones que se habían producido en la fase central de este séptimo repartimiento.

43 TORRES FONTES, J., Repartimiento de Orihuela..., pág. 121.

44 Esta parte del documento se encuentra en muy mal estado, lo que dificulta extraordinariamente la lectura del texto. 
Como punto final hay que decir que este séptimo repartimiento de Orihuela, responde más que a un proceso de colonización y repoblación a un proceso de regularización de propiedad ${ }^{45}$ y de consolidación de colonos en un área estratégica para las necesidades militares y defensivas de la villa en un espacio fronterizo. Este repartimiento llegó a afectar a cerca de quinientos colonos de la villa de Orihuela, repartiéndose tierras de secano en una extensión cercana a las once mil quinientas tahúllas.

\begin{tabular}{|c|c|c|c|}
\hline \multicolumn{4}{|c|}{ TOTAL DE TIERRAS REPARTIDAS EN 1330.} \\
\hline CUADRILLA & PEONÍAS & CABALLERÍAS & TOTAL (Tahúllas) \\
\hline 1 & 36 & - & 720 \\
\hline 2 & 6 & - & 120 \\
\hline 3 & 13 & & 260 \\
\hline 4 & 45 & 2 & 980 \\
\hline 5 & 13 & - & 260 \\
\hline 6 & 21 & - & 420 \\
\hline 7 & 3 & - & 60 \\
\hline 8 & 5 & - & 100 \\
\hline 9 & $?$ & $?$ & $?$ \\
\hline 10 & 18 & - & 360 \\
\hline 11 & 3 & 18 & 780 \\
\hline 12 & $?$ & $?$ & $?$ \\
\hline 13 & 15 & 1 & 340 \\
\hline 14 & 91 & 27 & 2900 \\
\hline 15 & 1 & 6 & $270 *$ \\
\hline 16 & 26 & 17 & 1200 \\
\hline 17 & 6 & 6 & 360 \\
\hline 18 & $101^{* *}$ & 1 & 2160 \\
\hline TOTAL & 399 & 77 & 11290 \\
\hline
\end{tabular}

* Hay 10 tahúllas más, ya que una de las caballerías era de 50 tahúllas.

** 10 peonías de 30 tahúllas

FUENTE: A.M.O. Contestador, n. ${ }^{\circ}$ 9. Elaboración propia.

45 A.M.O. Contestador, n. ${ }^{\circ}$ 9, f. 100v. (1330, 01, 08 ). 
El resultado final exacto del proceso del séptimo repartimiento fue el reparto de 399 peonías y 77 caballerías sobre un total de 11.290 tahúllas, que aproximadamente serían $13.378 .650 \mathrm{~m}^{2}$.

Los datos de los siete repartimientos y la prolongada duración de los mismos en el tiempo, prolongándose de 1265 a 1330, evidencian un poblamiento intenso tras la conquista cristiana del territorio, que llevó a una ocupación "plena" del territorio, abarcando incluso las zonas periféricas o fronterizas de la Gobernación de Orihuela, bajo el estímulo de esta nueva población cristiana y las amplias posibilidades económicas que ofrecían los recursos del alfoz del término de Orihuela.

\section{LA NECESIDAD DE DELIMITAR EL ESPACIO. LA EXPLOTACIÓN DE LOS RECURSOS ECONÓMICOS EN UN ESPACIO FRONTERIZO}

En los espacios fronterizos, los territorios limítrofes ofrecen posibilidades de obtener botín y riqueza del mismo, mediante la guerra o acciones puntuales de saqueo, verbigracia, captura de cautivos para su venta o canje, y el aprovechamiento de los recursos naturales y la obtención de beneficios económicos, como la recolección del junquillo, la elaboración de sosa, la utilización de los pastos, la obtención de carbón en las carboneras, la caza, etc.

En la Gobernación de Orihuela, las autoridades municipales de Orihuela con la complicidad de la Monarquía, realizaron desde la segunda mitad del siglo XIII y hasta el final de la Edad Media, acciones de gobierno tendentes al control de todos los espacios susceptibles de ser aprovechados para cualquier tipo de explotación económica. Así se reguló de forma cada vez más minuciosa el uso de los pastos, bosques, saladares, lagunas, ríos, etc., que se encontraban dentro del término o alfoz municipal de la ciudad de Orihuela. Fue este tipo de acciones lo que desencadenó la necesidad de acometer con la mayor precisión posible el amojonamiento del territorio fronterizo con el reino de Murcia.

Referido a un espacio de singular importancia para la explotación económica del territorio y para el objeto de este estudio, la veredas reales, con la conquista cristiana, se decidió en primer momento, el respeto al recorrido de las veredas tradicionales en el territorio.

Las rutas de las veredas en Orihuela, no sufrieron ninguna modificación, ya que constatamos en el libro del repartimiento, la decisión de las autoridades reales en época de Alfonso X, de respetar el trazado de las veredas de la época islámica. En el cuarto repartimiento, aparece recogida una disposición regia indicando que las veredas deben permanecer como en tiempos de mo- 
$\operatorname{ros}^{46}$, "...et las plazas et las salidas de los ganados que sean et que finquen asi como eran en tiempo de moros".

Tras la recesión del siglo XIV uno de los aspectos más importantes de la reordenación agrícola del Cuatrocientos es la intensificación del cultivo del trigo y el desarrollo de la industria textil. ${ }^{47}$

Fenómeno paralelo es la creciente privatización de pastos y otros recursos naturales que se producirá en el término durante el siglo XV a instancias de los dueños de heredades.

Entre 1415 y 1417 la corona autorizó y confirmó la privacidad de los pastos de los dueños de las alquerías, quienes se habían quejado ante el rey por la entrada de ganado en sus propiedades. Basaban su reclamación en un fuero de Jaime I que prohibía entrar reses en las alquerías de la huerta. ${ }^{48}$ En 1415 Fernando I dio la razón a la súplica presentada por los dueños de seis alquerías, concediendo sendas dehesas. Por ello ordenaba al justicia civil el estricto cumplimiento del fuero y la aplicación de las penas pertinentes a los infractores que metiesen animales en las propiedades de los demandantes. De esta forma la orden real privatizaba los pastos en estos lugares. ${ }^{49}$

46 Esta referencia aparece recogida en la edición de Torres Fontes del Libro de Repartimiento, en un capítulo que recoge las instrucciones de los partidores mayores para el desarrollo de la cuarta partición. Este texto no está incluido en el códice del libro de Repartimiento de Orihuela. Es un texto añadido por el editor, entre la transcripción del tercer repartimiento y la del cuarto repartimiento. TORRES FONTES, J., Repartimiento de Orihuela... pág. 51.

47 IRADIEL, P. "L'evolució econòmica", Història del País Valencià. Vol. II. De la conquesta a la Federació Hispànica. Barcelona. Edicions 62, 1989, pág. 277. BARRIO BARRIO, J.A., "Las reformas de la industria textil pañera en la ciudad de Orihuela en la primera mitad del siglo XV", Miscelánea Medieval Murciana. Universidad de Murcia, XXI (2007), págs. 39-68.

48 COLON, G. i A. GARCÍA. Furs de Valencia. Vol. I, Barcelona, 1980, Llibre I, Rubrica II, Fur IV, p. 114.

49 Alquería de Alquanyecia perteneciente a los herederos de Guillén Pérez Vayello, una alquería sin nombre de Antic Arboredes, la alquería de Moquita de Joan Pérez Vayello, una alquería sin nombre de Gines Silvestre, la alquería de Benimancoix de los herederos de Bertomeu Togores y una alquería en la puerta de Murcia con 160 tahullas de Pere Gil, platero. Todos estos personajes pertenecían a la oligarquía local. En 1417 Alfonso V confirmó la prohibición sobre la alquería de Gines Silvestre, la de los herederos de Guillén Pérez Vayello y la de los herederos de Bertomeu Togores. Se observa que en estos casos los límites de las alquerías aparecen fijados con más detalle que en los documentos precedentes de 1415. A(rchivo) de la C(orona) de A(ragón). reg. 2375 , f. 161v. 1415 , agosto, 2. reg. reg. 2375, ff. 162v-163r. 1415, julio, 5. reg. reg. 2375, ff. 163 r-v. 1415, agosto, 2. reg. 2375, ff. 164v-165r. 1415, julio, 5. reg. 2376, ff. $114 \mathrm{v} .1415$, agosto, 3. reg. 2377 , ff. 18 r-v. 1415, agosto, 1. reg. 2460, ff. 106v-107r. 1417,9 , 25. reg. reg. 2460, ff. 107 r-v. 1417, septiembre, 26. reg. 2460, ff. 107v-108r. 1417, septiembre, 25. 
En 1435 se acotó y amojonó en la partida del Río de Climent un espacio que se iba a destinar a la erección de la ermita de San Ginés del Río de Climent. Además el municipio prohibió que entrase ganado dentro de dicho término. ${ }^{50}$ El mismo año el Consell estableció un boalar en el almarjal de Almoradí para los animales de labranza de dicho lugar, prohibiendo la venta de hierbas a los hacendados del lugar, quedando reservadas para el uso mencionado. ${ }^{51}$ También prohibió la venta de las hierbas a los dueños de heredades en la huerta, tanto de regadío como de secano, en la zona que iba desde el pozo de Sancho Navarro hasta el delmari de Guardamar. ${ }^{52}$ Estas dos medidas sólo se aplicaron en dicho año y evidencian posiblemente un retroceso de los bienes comunales ante la venta de parte de dichos recursos por los propietarios, y como estas acciones privatizadoras limitaban el acceso a los pastos del término a una parte del campesinado como era el caso de Almoradí, cuyos habitantes ya habían tenido problemas del señor de La Daya por llevar a pastar su ganado a dicho lugar. ${ }^{53}$

En la segunda mitad del siglo XV se reaviva la tendencia privatizadora, y entre $1459^{54}$ y 1470 la corona concede diversos privilegios de dehesa sobre heredades $^{55}$ situadas en Orihuela y Guardamar ${ }^{56}$. Para obtenerlos los propietarios reclamaban al rey el cumplimiento de los fueros que prohibían entrar animales en tierra ajena y se quejaban ya que sufrían en sus propiedades el robo de leña, madera, paja y la entrada de ganado ajeno. ${ }^{57}$

Uno de los factores más destacados en la organización espacial del siglo $\mathrm{XV}$ es la delimitación del aprovechamiento de los recursos naturales. Su uso se va a ir fijando con precisión tanto por la intervención de la Corona como

50 El documento recoge los límites de los mojones colocados para la erección de la Ermita de San Ginés. A.M.O. Contestador, n. ${ }^{\circ}$ 22, f. 14r. 1435, enero, 12.

51 A.M.O. Contestador, n. ${ }^{\circ}$ 22, f. 16 r-v. 1435, febrero, 13.

52 A.M.O. Contestador, n. ${ }^{\circ} 22$, f. 23v. 1435, marzo, 9.

53 A.M.O. Contestador, n. ${ }^{\circ} 19$, f. 58v. 1421, abril, 1.

54 Sobre la concesiones de 1459 vid. BARRIO BARRIO J.A., "El señorío de la Daya y el municipio de Orihuela en el siglo XV", Señorío y Feudalismo en la Península Ibérica. (ss. XII-XIX), Zaragoza, 1993, III, págs. 259-270.

55 En unos casos se trataba de alquerías, en otros de cañadas y en ocasiones de propiedades que por su limitada extensión no eran consideradas como alquerías.

56 En 1459 Julián Monsi Castanyeda que posee una alquería en Guardamar y Berenguer y Ginés Silvestre que poseen la alquería de Benijofar, la cañada Pollera, la heredad dels Molins y el corral de Bodi en Guardamar. En 1460 Matheu Prohençal sobre una cañada en la partida de Rabat en Orihuela, y en 1470 Alfonso Gómez, notario, sobre diversas cañadas en la partida de Rabat en Orihuela. En todos los casos las propiedades aparecen perfectamente delimitadas en la documentación.

57 A.R.V. Real, 89, ff. 26v-27v. 1459, marzo, 15. Real, 89, ff. 31v-32r. 1459, abril, 4. Real, 92, f. 105v. 1460, abril, 5. Real, 293, ff. 139 r-v. 1470, diciembre, 20. 
por la de las autoridades locales. En este proceso se impondrán los intereses privados sobre los usos comunales, a la vez que las comunidades locales -municipios- entran en colisión en la defensa de la utilización de sus recursos propios frente a la intrusión foránea. En este caso Orihuela pugnará con Murcia y con Elche en el uso recíproco de los pastos y por la utilización de los mudéjares ilicitanos del junquillo y la realización de sosa en el término oriolano.

A nivel local las autoridades controlaran el uso de recursos como la leña, madera, hierbas, pastos, agua, sal, etc. y la elaboración de carbón, reservados para beneficio de la comunidad local y por ende para los propietarios de heredades que privatizaran estos bienes, en un proceso que es general en todos los municipios del mediodía del reino de Valencia.

Tenemos varios ejemplos sobre estos usos ilegales de recursos y espacios fuera de los términos concejiles o regnícolas de cada territorio. El 21 de febrero de 1417 se iniciaba la sesión del Consell de Orihuela, con una información que habían recibido las autoridades locales oriolanas, sobre la elaboración de carbón vegetal por vecinos de Murcia, en unas carboneras situadas en término municipal de Orihuela. Además labradores murcianos labraban en las tierras de Puig d'Albes, situadas en término concejil de Orihuela. El Consell ordenó que el Justicia criminal y los jurados nombrasen una comisión de "hòmens bons" para que con el escribano de la Gobernación acudiesen al lugar, para constatar que se estaban utilizando espacios y recursos del término de Orihuela y en ese caso confiscar las carboneras y las azadas y útiles de labor a los murcianos ${ }^{58}$.

En 1460 la villa de Elche requisó ganado oriolano, vacas, caballos, alegando que habían entrado a pastar en el término concejil ilicitano ${ }^{59}$.

Este mismo año se suscitó un conflicto territorial entre la villa de Elche y el lugar de Crevillente contra la ciudad de Orihuela. En reunión del Consell de Orihuela, se recogió la queja de los vecinos de Catral, que labraban las tierras del término de Orihuela como habían realizado todos los años, cuando fueron asaltados violentamente por gente armada de Elche y Crevillente, dirigido por el Baile de Elche, alegando que estas tierras no eran término de Orihuela, sino que se encontraban en Crevillente, que pertenecía al dominio de la villa de Elche, por lo que fueron denunciados, y detenidos a instancia del Baile de Elche por el lugarteniente de Gobernador y encerrados, unos en la prisión de la sala y otros en la prisión común de la ciudad de Orihuela ${ }^{60}$.

58 A.M.O. Contestador, n. ${ }^{\circ} 16$, f. 45r. (1417, febrero, 21$)$.

59 A.M.O. Contestador, n. ${ }^{\circ} 31$, f. $45 v$ (1460, abril, 6).

60 A.M.O. Contestador, n. ${ }^{\circ} 31$, f. 86r. (1460, septiembre, 29). 
2.1. Un debate fronterizo en torno a las Siete Higueras y los mojones del territorio

La primera referencia expresa y textual al término o topónimo "Siete Higueras" lo hemos localizado en un documento inédito del Archivo Municipal de Orihuela.

En abril de 1417 se suscitó un debate fronterizo entre los concejos de Murcia y Orihuela en torno a los límites jurisdiccionales en la zona conocida como el pozo de las Siete Higueras. El detonante de este conflicto de lindes, fue el apresamiento que realizaron los caballeros de la sierra, del reino de Murcia, a vecinos de Orihuela de una perra bermeja, de un hurón y de cuatro capillos que estaban utilizando en su actividad de caza menor en la zona de las Siete Higueras. Estos bienes les fueron confiscados a los hijos de Pla Xorquera y a Joan Garcia el jueves 8 de abril. Uno de los oriolanos tenía un rocín blanco y estaban todos cazando cerca de la cueva que se denominaba del pozo de las Siete Higueras. Queremos resaltar que esta es la primera vez que consta en la documentación medieval, la aparición del topónimo Siete Higueras, que se puede asociar al actual término municipal de Pilar de la Horadada.

Hay una noticia posterior de 1435, en la que vuelve a aparecer el topónimo Siete Higueras. Es una noticia sobre la utilización económica de la zona de Pilar de la Horadada en el siglo XV, recogida en un apunte contable, en las cuentas municipales del Clavario de Orihuela.

"Item en lo dit dia lo dit en gabriel despuig clavari damunt dit posa en despesa que despes en la anada que faheren en ferrando ximenez e en johan guilabert al pou de les set figueres on avien pres la sardina als de callosa ab certs hòmens que anaven ab los sobre dits segonsque los jurats hon han comptat... ${ }^{61 "}$

En la reunión del Consell de Orihuela del 18 de abril de 1417 fue leída una carta escrita el día 14 de abril por las autoridades de Murcia ${ }^{62}$, y en la que respondían a una carta que anteriormente les habían enviado las autoridades de Orihuela, presentando una queja formal por la actuación de los caballeros de la Sierra de Murcia ${ }^{63}$, ya que las autoridades municipales de Orihuela entendían que los vecinos de Orihuela estaban cazando en término municipal de Orihuela, por lo que las confiscaciones habían sido ilegales. Las autoridades de Orihuela pedían la restitución de los bienes confiscados a sus dueños,

61 A.M.O. Contestador, n. ${ }^{\circ} 1041$, Clavaria año 1435 , f. 49v.

62 A.M.O. Contestador, n. ${ }^{\circ} 16$, ff. 70 r-v. (1417, abril, 14).

63 Sobre los caballeros de la Sierra, vid. ORTEGA CERVIGÓN, J.I., "Los caballeros de la Sierra y la vigilancia de montes en la Baja Edad Media castellana", Miscelánea Medieval Murciana, XXXVII (2013), págs. 155-164. 
alegando que estaban cazando en término de Orihuela. La actuación de los caballeros de la sierra, organización militar del concejo de Murcia, creada para la guarda y vigilancia de los montes, evidencia la presión militar a un lado y otro de la frontera entre los alfoces municipales de Murcia y Orihuela, por el uso y aprovechamiento de los recursos naturales.

Las atribuciones de los caballeros de la Sierra de los concejos castellanos consistían en "figuraba la obligación de visitar el término para vigilar y comprobar mojoneras; velar por la conservación de los montes, impidiendo los daños - prender fuego, talar los árboles, cortar o sacar leña o madera, tener colmenas o hacer carbón sin licencia- o castigando a sus autores; evitar que los pastores quebraran aljibes con objeto de obtener agua para su ganado y que se cazaran conejos y liebres con perros; evitar que los ganaderos cortaran ramas para alimento del ganado o que introdujeran ganado en el huerto, como recogen las ordenanzas de Murcia, o en sembrados antes de obtener la cosecha, ni en las viñas antes de recolectar el fruto; examinar los ganados para sancionar al que tuviese en aparcería con otro y no fuese vecino del territorio; asimismo, no cazar en tiempo vedado o sin licencia concejil, castigar la pesca con instrumentos vedados y cobrar el montazgo a los forasteros que, sin licencia regia o concejil, entrasen a pastar en los términos concejiles" ${ }^{64}$.

Estas competencias tan amplias, facultaban a los caballeros de la Sierra, para intervenir en el impreciso linde fronterizo, sobre cualquier actuación de vecinos de Orihuela, que pudiese afectar a sus atribuciones, lo que generaba continuos roces en la raya fronteriza.

No hemos localizado todavía la carta original enviada desde Orihuela, aunque la respuesta redactada por las autoridades de Murcia, nos permite reconstruir perfectamente los hechos en torno a la situación del pozo de las Siete Higueras, como espacio que delimitaba ambos territorios y era motivo de litigio y fue el detonante de la necesidad de realizar un amojonamiento del espacio entre los concejos de Murcia y Orihuela.

Las autoridades de Murcia respondían sorprendidas, alegando que el pozo de las Siete Higueras, la cueva y el pozo de Siscar estaban en término de la ciudad de Murcia, por lo que los vecinos de Orihuela no tenían que haber entrado a cazar en término de Murcia, sin la preceptiva licencia de las autoridades de Murcia. Dan por buena la confiscación de bienes realizada por los caballeros de la Sierra y no aceptan que se les devuelva a sus dueños. Terminaban conminando a las autoridades de Orihuela, sobre el perjuicio

64 ORTEGA CERVIGÓN, J.I., "Los caballeros de la Sierra y la vigilancia de montes...". p. 161. 
que podían recibir los vecinos de dicha villa si pretendían cazar en dicha zona, ya que actuarían los caballeros de la Sierra.

Tras la lectura de la carta en el consistorio de Orihuela, las autoridades oriolanas decidieron responder alegando que dicha cueva y el pozo de las Siete Higueras y el territorio cmprendido hasta la Piedra Blanca y el "Bol del Ruch" son término de la villa de Orihuela, por lo que deben devolver los objetos y bienes confiscados, ya que las actividades de caza realizadas por vecinos de Orihuela habían sido legales ${ }^{65}$.

Tras esta deliberación fue redactada una carta de respuesta firmada por el Gobernador de Orihuela y las autoridades municipales. En la misiva indicaban textualmente que es cierto en toda la tierra, y es sabido y conocido, que el término de la villa de Orihuela llega hasta la Piedra Blanca y de allí al "Bol del Ruch" y que el pozo de las Siete Higueras y la cueva y la fuente de Siscar están dentro del término de Orihuela. De dicha cueva y pozo hay más de una legua y medía hasta la mencionada Piedra Blanca y horno ${ }^{66}$.

Las autoridades de Orihuela recuerdan en su carta, que en numerosas ocasiones se han puesto en cuestión los límites y lindes de ambos términos, por las autoridades municipales de ambas localidades. Teniendo claro esto, y en nombre del rey reclamaban la devolución de los bienes confiscados.

Recordaban, además, a las autoridades de Murcia que las represalias, marcas, prendas, heridas y muertes y otros peligros y daños que se suscitasen sobre esta cuestión y que podrían ser denunciadas por el rey de Castilla, serían responsabilidad de las autoridades de Murcia.

Por último y sobre la advertencia de las autoridades de Murcia, vedando la caza a los oriolanos en el pozo de las Siete Higueras con la amenaza de la actuación de los caballeros de la Sierra, las autoridades de Orihuela indican que los vecinos de Orihuela no van a volver a cazar en el término de Murcia, pero que los vecinos de Murcia tienen vedada la caza y hacer carbón en el término de Orihuela, entendiendo que el pozo de las Siete Higueras es término de Orihuela.

La proximidad en el tiempo, entre este debate fronterizo y el amojonamiento realizado en 1441, nos ilustran sobre los conflictos y tensiones que, de forma reiterada, se producían en el borde la frontera entre los vecinos de los municipios de Murcia y Orihuela. La solución acordada en 1441 fue

65 A.M.O. Contestador, n. ${ }^{\circ} 16$, ff. 72 r-73r. (1417, abril, 18).

66 La mención al horno en la carta redactada por las autoridades de Orihuela es muy escueta, no se indica el nombre del horno ni, por desgracia, su ubicación exacta. El interés de esta indicación geográfica es la indicación, por parte de las autoridades de Orihuela, de la existencia de un límite entre los términos de Orihuela y Murcia, ubicado en la zona denominada de la Piedra Blanca. 
una clara consecuencia de la necesidad de poner fin a estas querellas, tan perjudiciales, por otra parte, para el gobierno urbano de ambas ciudades y por ello podían resultar inconvenientes, para el ejercicio del poder, por parte de las respectivas oligarquías dirigentes de la capital del reino de Murcia y la capital de la Gobernación de Orihuela.

\subsection{Apresamiento de mudéjares en los límites fronterizos. Dudas sobre los mo-} jones del territorio. La necesidad de colocar nuevos mojones

El 27 de abril de 1417 se recibió una carta del Adelantado de Murcia en el consistorio de Orihuela, en relación a dos mudéjares de Abanilla que estaban presos en Orihuela, reclamando el Adelantado su liberación. Estos mudéjares habían sido detenidos por guardias enviados por el Gobernador de Orihuela y el Baile de Orihuela al camino que va de Abanilla a Aspe por cierta resistencia mostrada a sus requerimientos $u$ órdenes ${ }^{67}$.

Tras la lectura de la carta, en el Consell se hizo pública la información sobre los mojones que el Adelantado había mandado colocar en el linde del término de Murcia con el de Orihuela. Las autoridades de Orihuela entendían que dichos mojones se habían ubicado en término de Orihuela, por lo que se ordenaba al Justicia criminal y a los jurados el derribo de dichos mojones y la colocación de mojones nuevos en el lugar adecuado que debía marcar el límite entre ambos municipios ${ }^{68}$.

El mismo día las autoridades de Orihuela enviaron una carta al Gobernador, para informarle de diversos sucesos, como la cuestión suscitada por los mudéjares de Abanilla y la erección de mojones por el Adelantado de Murcia en los límites entre ambos términos ${ }^{69}$.

En reunión del Consell de 5 de mayo de 1417 se recibió una segunda carta del Adelantado en relación a la cuestión de los mudéjares de Abanilla, en la que requería a las autoridades oriolanas la necesidad de celebrar a la mayor brevedad posible una comisión para fijar con exactitud la jurisdicción

67 La detención o apresamiento de mudéjares, era una práctica habitual en la frontera entre el reino de Castilla y el reino de Valencia y también en la zona fronteriza con el reino de Granada. Sobre esta cuestión vid. FERRER I MALLOL, M. ${ }^{a}$ T. Els sarraïns de la Corona catalano-aragonesa en el segle XIV. Segregació i discriminació, Barcelona. Consejo Superior de Investigaciones Científicas. Institución Milá y Fontanals, 1987. Id., La frontera amb l'Islam en el segle XIV. Cristians i sarraïns al Pais Valencià. Barcelona. Consejo Superior de Investigaciones Científicas. Institución Milá y Fontanals, 1988.

68 A.M.O. Contestador, n. ${ }^{\circ}$ 16, ff. 82v-84r. (1417, abril, 27).

69 A.M.O. Contestador, n. ${ }^{\circ}$ 16, ff. 84v-85r. (1417, abril, 27). 
del lugar donde habían sido apresados los mudéjares ${ }^{70}$. Es decir, en este debate suscitado en torno a este conflicto jurídico, de nuevo como en el anterior relacionado con los derechos de caza, surgía la perentoria necesidad de delimitar con precisión los límites entre los términos de Murcia y Orihuela ${ }^{71}$.

En este sentido las autoridades locales de Orihuela, acordaron responder al Adelantado que estaban de acuerdo con celebrar la reunión que exigía, pero que deseaban contar con la presencia del Gobernador y del lugarteniente de Baile en la correspondiente declaración de términos. Para los munícipes oriolanos la declaración de los términos se debía realizar en el presente mes de mayo. Asimismo se debían precisar cuantos "hòmens bons" se debían elegir de la villa de Orihuela para participar en dicha comisión ${ }^{72}$. Todas estas actuaciones, se realizaban, a juicio y en palabra de las autoridades de Orihuela, al "servicio de Dios" y de los "señores reyes de Aragón y de Castilla"73.

La siguiente misiva fue enviada al Gobernador por las autoridades de Orihuela, informándole de esta cuestión y solicitando su presencia en Orihuela para formar parte de la comisión que tenía que realizar la declaración de términos entre Orihuela y Abanilla ${ }^{74}$.

En este año y como consecuencia de estos sucesos el Consell de Orihuela reunido el 6 de junio de 1417, tuvo noticia que las autoridades de Abanilla habían colocado unos mojones en el término de la villa de Orihuela, "Item en lo dit Consell fos donat a entendre que los de Favanella an fet uns mollons en el terme de la dita Vila" (de Orihuela). El Consell ordenaba al Justicia criminal y a los jurados que examinen dichos mojones ${ }^{75}$. En la misma reunión se informó al Consell que los vecinos de Murcia seguían labrando y haciendo carbón en el término de Orihuela, por lo que se ordenó al Justicia criminal y a los jurados que envíen dos hombres a caballo a reconocer el término y ver si se ha perjudicado a la villa con la presencia de dichos vecinos de Murcia en el término de Orihuela ${ }^{76}$.

70 Sobre las prácticas de cautiverio en espacios de frontera vid. CULIÁÑEZ CELDRÁN, M.C., Las relaciones de Orihuela con la Frontera de Granada en el siglo XV: la cautividad. Murcia, 2015. Tesis doctoral.

71 La carta no fue copiada en el registro de actas correspondientes. En las reuniones del Consell de Orihuela era frecuente debatir sobre una carta recibida de otro municipio. El notario solía copiar el contenido de la epístola en las actas de dicha reunión. En otras ocasiones se mencionaba la recepción de la misiva, se debatía sobe ella, pero luego no era copiada por el notario.

72 A.M.O. Contestador, n. ${ }^{\circ} 16$, f. 90v. (1417, mayo, 9).

73 A.M.O. Contestador, n. ${ }^{\circ} 16$, ff. 91r-v. (1417, mayo, 9).

74 A.M.O. Contestador, n. ${ }^{\circ}$ 16, f. 92r. (1417, mayo, 9).

75 A.M.O. Contestador, n. ${ }^{\circ} 16$, f. 117r. (1417, junio, 6).

76 A.M.O. Contestador, n. ${ }^{\circ}$ 16, f. 117r. (1417, junio, 6). 
Vemos, por tanto, que tanto en la zona norte como en la franja sur del espacio fronterizo con Murcia, las tensiones sobre el control económico del territorio y la necesidad de fijar con precisión los límites jurisdiccionales, propiciaban la necesidad de establecer mojones y lindes definitivos en todo el borde de la frontera meridional entre el reino de Valencia y el reino de Murcia.

Por ello y al margen de la rivalidad política y militar, que mantenían Murcia y Orihuela, como capitales del reino de Murcia y de la Gobernación de Orihuela respectivamente, surgía la necesidad de alcanzar acuerdos y consensos, al menos en lo referente a la delimitación precisa de sus respectivos territorios y a la fijación de los correspondientes mojones.

La no resolución de conflictos y tensiones como los que se suscitaron a principios del siglo XV y la necesidad de acabar con este tipo de situaciones, fue otro de los motivos que concitó el consenso político entre las autoridades de Murcia y Orihuela, lo que permitió la elaboración del amojonamiento de 1441.

\subsection{Las Cinco Alquerías. El emplazamiento del consenso político entre Orihuela y Murcia}

Las tensiones que se podían derivar del uso de pastos, recursos naturales, caza, apresamiento de cautivos, etc., en las zonas fronterizas entre el reino de Valencia y el reino de Murcia, y que generaban confiscaciones de bienes, pleitos, recursos, etc, y que podían tener consecuencias virulentas para las poblaciones situadas a ambos lados de la frontera, se pudieron resolver de forma pacífica, en numerosas ocasiones, sobre todo a partir del siglo XV, con las iniciativas tomadas por las autoridades municipales de las ciudades de Murcia y Orihuela de nombrar comisiones formadas por miembros de los linajes más poderosos de ambos centros urbanos, para llegar a acuerdos de mediación y evitar consecuencias irreparables o enfrentamientos violentos, guerras, etc.

Para solventar estas "tensiones fronterizas" además de elegir a los miembros que formaban parte de dichas comisiones en representaciones de cada una de las capitales de la demarcación fronteriza, se solía designar un lugar "neutral" cercano a la frontera donde se pudiesen reunir cómodamente los comisionados. En numerosas ocasiones el lugar elegido fue las Cinco Alquerías, lugar donde se pactó la histórica delimitación de términos o amojonamiento realizada en 1441 y que fue determinante para evitar conflictos futuros entre ambas localidades.

En 1463 ante un conflicto suscitado por la entrada de gente armada de Orihuela en la huerta de Abanilla y el conflicto armado que se había desa- 
rrollado, se decidió nombrar una comisión formada por representantes de Murcia, del Comendador de Calatrava, del Obispado y de Orihuela. El lugar elegido para celebrar las deliberaciones fue las Cinco Alquerías ${ }^{77}$.

En reunión anterior celebrada el 31 de diciembre de 1462 del Consell de Orihuela se recibía una carta de Murcia, en la que se expresaba esta voluntad conciliadora y resolutiva hacia una conclusión pacífica de los conflictos fronterizos.

"E primerament lo dit Consell attes que...regidors de la Ciutat de Murcia han scrit e molt plegat los dits officials que aquelles trametesen persones de les cinch alqueries ab los quals poguessen comunicar e veure si los fets e differencies de Favanella ab la dita ciutat poguesen pendre qualque per bon medi de pacifich a per als qui iran sia stat trames guiatge e segur del noble Adelantat de Regne de Murcia ..."78

\section{LA DEFINITIVA DELIMITACIÓN TERRITORIAL. EL PRIMER AMO- JONAMIENTO DEL SIGLO XV (1441)}

La Sentencia Arbitral de Torrellas de 1304 y el Acuerdo de Elche de 1305, fijaron de forma definitiva las fronteras entre el reino de Murcia y el reino de Valencia, lo que no impidió que durante los siglo XIV y XV, la presión humana sobre los espacios fronterizos y la necesidad de utilizar todos los recursos económicos disponibles, a ambos lados de la frontera, pastos, uso agrícola de la tierra, carboneras, caza, etc., generara numerosos conflictos territoriales a un lado y otro de la frontera.

La necesidad de acabar con estos reiterados y constantes conflictos y que tenían que resolverse a través de disputas legales suscitadas entre los concejos de Murcia y Orihuela, fue un acicate para alcanzar un acuerdo definitivo sobre los mojones. Además para el seguimiento y resolución de estos pleitos y conflictos, las autoridades municipales de ambos municipios, tenían que enviar a embajadores para realizar las pertinentes gestiones diplomáticas ante las autoridades del municipio rival. Estas gestiones diplomáticas, judiciales y burocráticas suponían un elevado coste para las arcas municipales.

Esta continua falta de definición de los límites exactos de los lindes fronterizos entre ambos concejos, tenía también repercusiones negativas sobre los intereses económicos de los miembros de las oligarquías locales de ambas localidades, ya que sobre el aprovechamiento económico de las tierras

77 A.M.O. Contestador, n. ${ }^{\circ}$ 31, f. 13r. (1463, enero, 4.).

78 A.M.O. Contestador, n. ${ }^{\circ}$ 31, f. 11 r (fol antigua). 254r. (1462, diciembre, 31). 
lindantes gravitaban importantes intereses económicos, como el uso de los pastos, el paso de ganados, la caza, la elaboración del carbón vegetal, etc.

En 1441 las autoridades municipales de Murcia y Orihuela decidieron llegar a un acuerdo mutuo para fijar de forma definitiva los lindes en la zona meridional de ambos términos, a través del establecimiento de unos mojones que marcarían los lugares exactos por donde discurría la línea fronteriza entre ambos municipios y por extensión entre el reino de Valencia y el reino de Murcia.

Esta decisión era muy importante, ya que en la práctica suponía colocar mojones sobre la línea fronteriza fijada en la Sentencia Arbitral de Torrellas de 1304 y el Acuerdo de Elche de 1305. Estos dos tratados diplomáticos rubricados por la Corona de Castilla y la Corona de Aragón, seguían vigentes en el siglo XV, pero su ejecución y aplicación en el día a día generaba numerosos problemas de orden práctico, por la imprecisión de los límites exactos y de lo acordado en Torrellas y en Elche a principios del siglo XIV.

\subsection{La reunión previa al acuerdo definitivo. Septiembre de 1441}

El 21 de septiembre de 1441 se celebró una reunión previa a la firma del acuerdo definitivo sobre los mojones de la frontera meridional. Las Cinco Alquerías, fue el lugar elegido para las reuniones entre los representantes del concejo de Murcia y los del concejo de Orihuela. Las reuniones que se celebraron en la casa que allí tenía Joan Vicente, tenían el objetivo de poder llegar a un acuerdo entre ambos municipios y así fijar unos mojones, para poder realizar la exacta y precisa delimitación territorial entre ambos municipios.

La representación de la ciudad de Orihuela estaba compuesta por Lluís Soler, Jaume Rocamora y Bertomeu Monsí de Castanyeda, miembros de la oligarquía oriolana. Habían sido elegidos como diputados o comisarios por el noble Pere Maça de Liçana, Gobernador de Orihuela y por el Consell de Orihuela. La representación de la ciudad de Murcia estaba formada por Pedro González Arróniz, caballero y alguacil, Ferrando Rodríguez de la Cerda y Pedro Bernal, regidores, designados por el noble Alfonso Yáñez Fajardo, Adelantado Mayor del reino de Murcia y por el concejo de Murcia.

Los diputados o comisarios de ambos municipios, habían sido designados con la misión de realizar la partición de los límites entre ambos municipios, en la zona del río Segura hasta el mar, en la parte del medio día.

También participaron expertos de ambas localidades, Bertomeu Cascant, conseller de Orihuela y Nicolas Ferrer y Garcia Jofre, jurados de Murcia, alegando el conocimiento que tenían de la zona. También fueron consultadas 
personas ancianas conocedoras del espacio geográfico a delimitar, para poder actuar con mayor precisión y conocimiento de causa ${ }^{79}$. En la Edad Media era habitual recurrir a las personas que conocían o podían saber algo sobre los lindes y parcelas de un territorio, para poder contar con su testimonio ${ }^{80}$. En la documentación conservada sobre el amojonamiento entre las ciudades de Murcia y Orihuela, por desgracia, no se ha registrado el testimonio de las personas ancianas consultadas ${ }^{81}$.

En esta reunión se acordaron los límites precisos del territorio y los lugares exactos donde debían ser colocados los mojones.

El acuerdo fue aceptado y aprobado por los concejos de ambas ciudades, el Adelantado del reino de Murcia en nombre del rey de Murcia y el Gobernador del reino de Valencia en nombre del rey de Valencia. Los capítulos del deslinde quedaron plasmados en un documento jurídico de delimitación de términos y mojones firmado por ambas partes y con dos originales y dos copias, redactados en las lenguas utilizadas por las administraciones de ambos reinos, en catalán el documento original para las autoridades de Orihuela y la copia para las autoridades de Murcia $^{82}$ y en castellano ${ }^{83}$ el documento original para las autoridades de Murcia y la correspondiente copia para los gobernantes oriolanos.

Las cláusulas del acuerdo fueron aprobadas ante los concejos generales de ambas ciudades y con la presencia de las autoridades que representaban el poder de la Monarquía en la zona, el Adelantado del reino de Murcia y el Gobernador de Orihuela. Además en las reuniones donde fue aprobado y ratificado el amojonamiento del término, se contó con la presencia de destacadas personalidades de ambas ciudades, los llamados "bons hòmens" en la ciudad de Orihuela y auténtica representación de la oligarquía local.

79 A.M.O. D-2497, f. 139r. (1441, septiembre, 21).

80 FOSSIER, R., Gente de la Edad Media. Madrid. Taurus, 2007, págs. 294-295. Sobre los testimonios de los campesinos en las pesquisas de términos. Vid. MONSALVO ANTÓN, J.M. ${ }^{a}$, Comunalismo concejil abulense. Paisajes agrarios, conflictos y percepciones del espacio rural en la Tierra de Ávila y otros concejos medievales. Ávila, 2010, pp. 14-15.

81 Ello nos hubiera permitido disponer de la "voz directa" recogida en dichos testimonios. Sobre los conceptos "voz directa", "expresiones directas", "historia oral retrospectiva”, vid MONSALVO ANTÓN, J.M. a , Comunalismo concejil abulense...pp. 14, 259, 266, 370, 389, 403 y Anexo III (pp. 404-420). Esta obra plantea unas perspectivas teóricas y metodológicas muy novedosas sobre el análisis de la documentación judicial que incluye testimonios directos de individuos, declaraciones, confesiones, denuncias, etc.

82 A(rchivo) M(unicipal) de MU(rcia). Pergaminos, n. ${ }^{\circ}$ 132. (1441, octubre, 19).

83 AMMU. Pergaminos, n. ${ }^{\circ}$ 131. (1441, octubre, 22). 
"E lo dit senyor gobernador e nosaltres essén certificats per los dits nostres diputats de tot ço que dits dessus e del punt que la dita concòrdia havia romàs ffem venir en lo dit consell, ultra los dits consellers, certs bons hòmens de la dita Ciutat en convinent nombre" ${ }^{\prime 4}$.

Se acordaba además de forma solemne la perpetuidad del acuerdo, como tratado solemne y justo que debía ser de obligado cumplimiento para las dos partes, reino de Murcia y reino de Valencia y para todos los sucesores de los firmantes y de sus representados en ambos reinos y "para siempre jamás".

Esta disposición o cláusula del acuerdo es decisiva, ya que muestra que fue un acuerdo diplomático adoptado a perpetuidad y para siempre jamás entre dos reyes, Juan II de Castilla y Alfonso V de Aragón, a través de sus representantes oficiales, y dos municipios, Murcia y Orihuela, a través de sus instituciones representativas, el Concejo de Murcia y el Consell de Orihuela.

La no revocación posterior de este acuerdo, evidencia que esta delimitación sigue jurídicamente vigente en la actualidad ${ }^{85}$, entendida como disposición que delimitaba de forma precisa los límites acordados en la Sentencia Arbitral de Torrellas de 1304 y el Acuerdo de Elche de 1305, estableciendo los correspondientes hitos o mojones que señalaban los lugares precisos por donde discurría dicha raya o límite entre ambos municipios y reinos. Siendo dicha raya o límites y mojones los que siguen vigentes en la actualidad.

\subsection{El acuerdo definitivo. La delimitación de mojones de 1441}

El documento del acuerdo se inicia con un exordio muy ilustrativo. Las autoridades firmantes del documento, Adelantado Mayor del reino de Murcia, Gobernador de Orihuela, y autoridades municipales de Murcia y Orihuela, justifican la importante actuación que van a acometer, poniendo el énfasis en

84 AMMU. Pergaminos, n. ${ }^{\circ}$ 132. (1441, octubre, 19).

85 En 2009 el Instituto Geográfico, dependiente del Ministerio de Fomento, dio la razón al municipio de Pilar de Horadada, en el pleito que mantenía con el municipio murciano de San Pedro del Pinatar, que previamente había desplazado los mojones de su término, ocupando parte del espacio del término municipal de Pilar de la Horada. Para decidir el litigio, cada municipio presentó un municipio elaborado por un equipo de expertos. San Pedro del Pinatar, presentó un informe avalado por profesorado de la Universidad de Murcia, sobre la base de un amojonamiento de 1897, mientras que Pilar de la Horadada presentó un informe elaborado por un equipo de investigadores de la Universidad de Alicante, del que formé parte. El informe de Pilar de la Horadada se basaba en una revisión de amojonamientos realizada en 1756, basada en el primer amojonamiento de 1441. El artículo tiene su base en el informe que elaboramos en el contexto del proyecto de investigación financiado por el ayuntamiento de Pilar de la Horadada "Estudio de los límites históricos que separan los municipios de Pilar de la Horadada y San Pedro del Pinatar". 
que sus acciones están basadas en "la sagrada sabiduría de Díos y las sagradas escrituras, la base del conocimiento para lograr acuerdos y paces entre las gentes. Verdades predicadas por Jesucristo y que sirven para atemperar el coraje de los hombres y concordar los enemigos que están en discordia esto lo deben desear todos los hombres y sobre todo los concejos y universidades (municipios) ${ }^{86}$, aunque pertenezcan a diferentes reyes o señorías, siempre que sus reyes o señores se encuentren en paz".

Frente a estas buenas intenciones, el documento recuerda que las discordias entre los concejos suelen ser muy perjudiciales para los pobladores de cada territorio, por lo que los que tienen asignadas las tareas de gobernar deben esforzarse para que estas discordias desaparezcan.

Para lograr este objetivo tanto el concejo de Orihuela como el Concejo de Murcia, con la aprobación del Gobernador de Orihuela y el Adelantado del reino de Murcia, han llegado a un acuerdo para que cesen daños como muertes, heridas, robos, apresamientos, injurias, incendios, talas, pérdidas de bienes, gastos y algunos inconvenientes más que solían producirse entre las autoridades de ambas ciudades. Una de las causas de estos conflictos fronterizos y de términos, era la imprecisión de los límites exactos entre ambos municipios. El acuerdo de mojones quería poner fin a estas tensiones y conflictos endémicos.

Los expertos de ambos términos Bertomeu Cascant, de Orihuela, y Nicolau Ferrer y Garcia Jofre, de Murcia, debatieron entre ellos sobre la forma más conveniente de acometer el amojonamiento. Para alcanzar un resultado satisfactorio, consultaron con personas ancianas que conocían bien el territorio.

El primer resultado de sus pesquisas con los hombres ancianos, permitió establecer las zonas o áreas conflictivas en los límites entre ambos territorios que eran el Portichol d'En Tordera, la fuente amarga, la majada de las vacas, la scalerola de Pere Royz, llamada de las carboneras por los murcianos ${ }^{87}$, el pozo de las Siete Higueras y la Ceñola.

En esta zona los de Orihuela pasaban a ella diciendo que era suya y los de Murcia hacían lo mismo.

86 El documento alude a las universidades como la base del reconocimiento jurídico de una entidad de carácter municipal. Sobre el concepto de Universitas y su introducción en el reino de Valencia, vid. BARRIO BARRIO, J.A., "La introducción del término Uniuersitas en las instituciones municipales del reino de Valencia", NASCIMIENTO, A.A., ALBERTO, P.A., IV Congreso Internacional de Latim Medieval Hispânico. Lisboa, 2006, págs. 191-201.

87 En esta zona los murcianos hacían carbón vegetal, lo que explica el sentido del nombre puesto a esta zona. 
Los capítulos se redactaron para poner fin de forma definitiva a esta situación y fueron aprobados y ratificados por el concejo de Orihuela y el Gobernador de Orihuela el día 19 de octubre de 1441 y por el concejo de Murcia y el Adelantado del reino de Murcia el día 22 de octubre de 1441.

\subsubsection{Descripción de la ubicación de los mojones en el acuerdo de 1441}

El acuerdo de delimitación de términos de 1441, estableció la colocación de ocho mojones entre la frontera sur del reino de Valencia y la frontera norte del reino de Murcia, quedando definidos y descritos los lugares donde debían ser colocados los mojones.

Exponemos a continuación la ubicación de cada uno de los ocho mojones.

1. Se toma la línea que parte los términos en la huerta, delante de Beniafel, donde comienza la vía que del río Segura va al mar en la parte del medio día tomando línea derecha hasta salir del regadío y entrar en el monte y allí se haga un mojón, dejando la cañada de Marçalot (Marialot) y diezmarios de la parte de Orihuela y la cañada ancha en la parte de Murcia.

2. De este primer mojón vaya la línea derecha al portichuelo d'En Tordera en la parte de Orihuela. El mojón se debía hacer en el portichuelo, de modo que la fuente de Entordera, quedaba en la parte de Orihuela.

3. Desde el mojón del portichuelo d'En Tordera se debía tomar línea derecha hasta la fuente amarga y que se haga allí un mojón. Que la fuente sea tomada como mojón y común a ambos términos.

4. De la Fuente Amarga discurra una línea derecha a la majada de las vacas que está en el cabezo de la balsa de la Pinilla. Que allí se haga un mojón, quedando la balsa de parte de Murcia.

5. Del mojón de la majada de las vacas sea trazada una vía a la colina o collado de la escalerola que en Orihuela llaman de Pere Ruiz y los de Murcia llaman de las carboneras. Aquí se debe hace otro mojón.

6. De aquí se debe tomar vía derecha al pozo de las Siete Higueras. Aquí se debe hacer otro mojón, quedando el pozo por mojón y común a ambos términos.

7. Del pozo debe ir una línea derecha hasta la Cenyola del pinatar. Aquí se debe hacer un mojón, quedando la dicha Cenyola común a ambos términos y por mojón.

8. De dicha Cenyola sea tomada vía derecha al mar, donde será la mediana del término y confín y espacio que está entre el pinatar y el ginebral. Se debe hacer en la mediana del ginebrar y pinatar un mojón, 
quedando el pinatar con todo lo de la mano derecha de dicha línea y mojones que va del río Segura al mar en el término de Murcia. Y el ginebrar con todo lo que queda a la mano izquierda de dicha línea y mojones del río a la mar, en el término de la ciudad de Orihuela.

Los mojones debían ser construidos a costa de ambos municipios y realizados a cal y canto para que sean más estables y puedan durar más tiempo. Es decir, los mojones debían ser fabricados con cal y piedra (canto rodado).

\subsubsection{La validez jurídica actual de la delimitación de 1441}

El contenido del documento que establecía en 1441 la delimitación territorial entre los municipios de Orihuela y Murcia y el amojonamiento acordado en dicho acuerdo, debe ser entendido en primer lugar como una consecuencia jurídica de la Sentencia Arbitral de Torrellas de 1304 y al Acuerdo de Elche de 1305. En segundo lugar, entendemos la vigencia jurídica actual de todos estos acuerdos (Sentencia arbitral de Torrellas de 1304, Acuerdo de Elche de 1305 y Acuerdo de delimitación y amojonamiento de términos de 1441), ya que ninguno de ellos ha sido revocado, anulado, suspendido, derogado o corregido en lo referente a las decisiones acordadas en todos estos acuerdos o tratados.

Estos tres acuerdos jurídicos se adoptaron por árbitros, representantes o delegados de las dos monarquías implicadas en estos acuerdos, la Corona de Castilla y la Corona de Aragón y fueron aprobados y ratificados por sus respectivos soberanos. La Sentencia Arbitral de Torrellas y al Acuerdo de Elche por Fernando IV rey de Castilla y Jaime II soberano de la Corona de Aragón. La delimitación de términos quedaba confirmada y ratificada por Juan II rey de Castilla y Alfonso V soberano de la Corona de Aragón, en este caso a través de documento rubricado por los representantes de la Monarquía en la firma del documento de 1441, el Adelantado Mayor del reino de Murcia y el Gobernador de Orihuela.

En las cláusulas del acuerdo se indicaba de forma expresa, la vigencia jurídica plena, permanente y perpetua de lo acordado y de aplicación para las dos partes afectadas.

"E si neccessari es ho permetre axi per sa sentencia possant aquella pena o penes sobre aço que vell ben vist fos para que millor fos guardat per ell e per los seus successors governadors. E per nos e per los que vendran apres de nos per a sempre james. E obligam nos a major abundancia e a nostres successors en quant en nos sera e sera en ells de guardar e tenir e mantenir e complir e fer guardar e tenir e mantenir e complir esta dita concordia per a sempre james com en aquella es contengut e sera sentenciat per lo dit senyor gobernador segons e per la ma- 
nera e forma que los dits senyors Consell Alcaldes Alguacil e Regidors Cavallers scuders e hòmens bons de la dita ciutat de Murcia ab auctoritat e decret del molt noble senyor N'Alfons Yuanyes Fajardo Adelantat major del Regne de Murcia se han obligar enço que pertany a la sua part de la guardar e tenir e mantenir. E ço que que per ell sera pronunçiat e manat. E nos dit don Pero Maça de Liçana gobernador damunt dit qui present som entenent com seent cert que aquesta ditaq concordia e declaraçio de termens feta en la manera que dita es comple molt a servey del dit nostre Senyor Rey d'Arago..." 88

"E fuese mejor guardado por el e por sus sucesores adelantados e per nos e per los que viniesen despues de nos para siempre jamas. E obligamos nos a mayor abondamiento. E a los nuestros sucesores en quanto en nos sera e sera en ellos de guardar e tener e mantener e conplir e facer guardar e tener e mantener e conplir esta dicha concordia siempre jamas como en ella se contiene e sera sentenciado por el dicho sennor adelantado segund e por la manera e forma que los dichos sennores justicia e jurados e concejo con autoridad e decreto del muy noble sennor don Pero Maça de Lliçana e governador mayor estan obligados en lo que pertenece a la su parte de la guardar e tener e mantener e lo que por el es sentenciado e mandado. E yo el dicho Alfonso Yuanyes Fajardo adelantado mayor deste Regno de Murcia que presente so entendiendo e seyendo a esto que esta dicha concordia e declaracion de terminos fecha en la manera que dicha es [manchado] conplidesa a serviçio del dicho nuestro sennor el Rey de Cstilla e al provecho e utilidad de la Universidad e personas singulares desta dicha cibdad en quanto en mi es como adelantado. E por mis sucesores adelantados loo e aprovo e confirmo esta dicha concordia e declaracio de terminos" $"$.

\section{LA DEFINITIVA DELIMITACIÓN TERRITORIAL. EL SEGUNDO AMOJONAMIENTO DEL SIGLO XV (1462)}

El 10 de octubre de 1462 se acometió una segunda e importante delimitación de términos entre los municipios de Murcia y Orihuela ${ }^{90}$, con el deslinde y amojonamiento de la frontera norte de ambos territorios, la zona que iba del río Segura hasta la sierra de Santomera, en la zona del Campo de la Matanza. Para alcanzar el consenso fue designada una comisión, igual que en el deslinde de 1441, formada por procuradores designados por cada uno de los municipios. Por la ciudad de Murcia fueron nombrados Alfonso de Lorca, caballero y regidor y Pedro Ferret y Juan de Valladolid, jurados, y la ciudad de Orihuela nominó a Arnau Rosell, Francesc Silvestre, jurados de Orihuela

88 AMMU., Pergaminos, n. ${ }^{\circ} 132$.

89 AMMU., Pergaminos, n. ${ }^{\circ} 131$.

90 AMMU, Pergaminos, n. ${ }^{\circ} 139$. 
y Mosén Antoni de Galbe y mosén Joan Rocamora ${ }^{91}$, caballeros, con la presencia de Gómez Daroca, jurado de Orihuela.

Este deslinde supuso el amojonamiento de la frontera norte entre los municipios de Murcia y Orihuela, la zona que iba del río Segura hasta la sierra de Santomera y donde se encontraba el Campo de la Matanza y adquiere un gran valor histórico, dado que supone la culminación del proceso de delimitación precisa del territorio y amojonamiento del mismo iniciado con el deslinde de 1441. Con el acuerdo de 1462 se delimitaba de forma definitiva la frontera entre el reino de Valencia y el reino de Murcia, y por extensión, entre los términos municipales de la ciudad de Orihuela y la ciudad de Murcia.

También es interesante en este documento, la reiteración en la expresión "linea dreta" o "línea derecha" que de forma constante fue utilizada en la delimitación y amojonamiento de 1441, lo que nos permite definir su significado en los documentos de amojonamiento y delimitación de términos.

"...axi com comença del Riu de Segura a la vila de la serra de Sentomera linea dreta tro exir del regadiu...".

"...e de aquest primer mollo una linea dereta a una çeniola...".

"...e desde aquest dit segon mollo una linea dreta tro hun tancament o mota..."

"E que de aquest mollo una linea dreta tro al cami del dit Riu de Segura..."

Estos son algunos ejemplos que demuestran el uso constante y reiterado de la expresión línea derecha, que no indica su significado textual de una línea recta, sino que indica el punto de partida desde un mojón hasta el punto final en el que se debe establecer el siguiente mojón, pero sin que entre un mojón y el siguiente haya que trazar una línea recta.

Donde aparece con mayor nitidez todavía el significado real del término "línea derecha", en los documentos de delimitación de mojones, es en el documento relativo a la revisión de mojones de 1668.

En el exordio del documento aparece una referencia muy interesante sobre el sentido de la expresión "línea derecha":

91 En el estudio que hemos presentado, se puede destacar la presencia de miembros del linaje Rocamora, en el séptimo repartimiento y con un papel relevante en la comisión de notables designados por la ciudad de Orihuela para negociar los amojonamientos de 1441 y 1462. Llama la atención la pervivencia del linaje Rocamora, en puestos destacados del gobierno de la ciudad de Orihuela desde el siglo XIV al siglo XV y por ello y por los servicios prestados a la Monarquía su ascenso social del grupo de ciudadanos y al grupo de caballeros y la conformación de un señorío propio en el territorio en la segunda mitad del siglo XV. El linaje Rocamora, fue uno de los más poderosos en la ciudad de Orihuela en el siglo XV. Vid. BARRIO BARRIO, J.A., "Los procuradores del brazo real..." VILAR, J.B., Historia de la ciudad de Orihuela. Los siglos XIV y XV en Orihuela. Tomo III, Murcia, 1977, p. 150. 
"Escrivimos a V.S. Suplicandole mandase nombrar un comisario, que asistiese juntamente con Aquie nombrariamos a sacar de mojon a mojon la linea derecha que era en lo que podia haver diferencia, y con esto supieran todos lo que era suyo y se ebitaran las inquietudes que se podian seguir"92.

Por tanto, la expresión "línea derecha" o "linea dreta", utilizada de forma reiterada y constante en la documentación referente a deslindes de términos y amojonamientos, refiere a la acción de establecer una línea de un mojón a otro, sin que obvia y necesariamente dicha línea tenga que ser recta. La expresión indica, pues, la línea que discurre entre un mojón y el siguiente mojón referido.

\section{LAS REVISIONES DEL DESLINDE DE 1441. LAS COMISIONES DE REVISIÓN DE MOJONES (1668)}

Una vez que fue culminado el gran proceso de amojonamiento de la frontera, realizado en el siglo $\mathrm{XV}$, se siguió una práctica secular, que consistió en el nombramiento de comisiones de visitadores, encargadas de revisar y solucionar conflictos puntuales suscitados en torno a las zonas colindantes en el espacio amojonado y por otra parte, convocadas con cierta periodicidad para revisar el estado de los mojones y decidir en su caso, actuaciones de renovación de los mojones deteriorados.

Tras los deslindes de 1441 y 1462, se procedió a la definitiva delimitación de la raya fronteriza entre Orihuela y Murcia y el amojonamiento del territorio, siguiendo las disposiciones recogidas en ambos deslindes. Posteriormente se realizaron periódicas revisiones de la raya fronteriza.

Estas visitas a la raya fronteriza, no venían marcadas por ninguna disposición recogida en los acuerdos de 1441y 1462, sino que respondían a acuerdos concretos entre los municipios afectados, Murcia y Orihuela, con el fin de responder a debates o problemas puntuales surgidos en la utilización de las veredas o el uso de los recursos naturales disponibles en la raya fronteriza. Con dicho objetivo se nombraban comisiones de visitadores, que representaban a ambos municipios que se reunían en la zona de la raya fronteriza, para verificar el trazado de la línea, el estado de conservación de los mojones, la necesidad de reparar algunos de ellos, etc.

El control y revisión de los mojones que los concejos de Murcia y Orihuela habían ordenado construir en 1441 y 1462, fue realizado de forma periódica por emisarios, síndicos o mensajeros nombrados por ambas ciudades.

92 AMMU, CAM, 758, n. ${ }^{\circ}$ 9, f.12r. (1668, agosto, 31). 
La primera noticia que tenemos de estas características es la designación en 1443 de Jaume Rius, bachiller en leyes, como mensajero de Orihuela para negociar con las autoridades de Murcia, lo referente al pago de los mojones y la gestión y control de los mismos ${ }^{93}$.

Esta primera actuación fue el inicio de una metodología de trabajo que se ha mantenido durante varios siglos y ha consistido en la coordinación de acciones conjuntas entre los municipios de Murcia y Orihuela, para verificar de forma periódica el estado de los mojones, su posible deterioro, la necesidad de reemplazar los mojones deteriorados o destruidos por otros nuevos.

Mantenemos la hipótesis de que todos los deslindes posteriores a los realizados en el siglo $\mathrm{XV}$, fueron en realidad comisiones de visitadores o verificadores que revisaron y repasaron el estado de los mojones, sobre la base del deslinde y amojonamiento de 1441.

La primera visita de mojones de la que tenemos constancia, fue convocada en 1460, con motivo de un conflicto fronterizo suscitado en torno a los espacios amojonados. La ciudad de Orihuela planteó una queja al concejo murciano, alegando que los de Murcia habían derribado una mota edificada en el término de Orihuela y situada en el mojón de la puerta de Murcia. Para solucionar este conflicto entre ambos concejos, las autoridades municipales de Orihuela proponían nombrar una comisión de visitadores, encargada de acudir a la zona donde se había originado el conflicto, para buscar una solución consensuada entre ambas partes y formada por seis miembros representando a cada una de las dos localidades y designados por los concejos de cada ciudad ${ }^{94}$.

En reunión posterior del Consell se decidió el lugar donde se debían reunir los visitadores para iniciar sus deliberaciones.

"Que la dita visitacio e examinacio per les persones eletes per cascuna de les dites parts se fes dijous...e ques ajustasen a Santomera e que en apres per en Ffrancisco Perez scriva de la sala e consell de la dita ciutat de Murcia li havia dit que...los officiales de la dita ciutat de Murcia mudarien lo loch hon se devien asjutar a la alqueria den Bernat Calatayud terme de la dita ciutat de Oriola per ço que a Santomera no havia aygua dolc..."95.

La comisión de visitadores de 1668 fue designada para solucionar una cuestión suscitada por los vecinos de las partidas de Fuente Amarga y Alca-

93 AMMU Leg. 4286, n. ${ }^{\circ}$ 6. A.M.O. Contestador, n. ${ }^{\circ}$ 25, f. 63v. $(1443,07,02)$.

94 A.M.O. Contestador, n. ${ }^{\circ} 31$, f. 45v (1460, abril, 6). Reunión del Consell de Orihuela. A.M.O. Contestador, n. ${ }^{\circ}$ 31, f. 47 v. (1460, abril, 156). Carta del consell de Orihuela al concejo de Murcia.

95 A.M.O. Contestador, n. ${ }^{\circ}$ 31, f. 46v. (1460, abril, 15). 
chofas sobre la ubicación de tierras de labrantía y conflictos con vecinos del término contrario sobre el derecho de unos u otros al uso de dichas tierras.

Para solucionar la cuestión suscitada en torno a las tierras de cultivo, ubicadas en la partida de Fuente Amarga, las autoridades decidieron consultar la documentación más reciente referida a revisión de amojonamientos. Las autoridades de Orihuela ante la petición cursada por sus homónimos de Murcia, se comprometieron a localizar en su archivo los datos del amojonamiento de 1610. La petición había sido cursada desde Murcia en noviembre de 1685. No obteniendo respuesta en abril de 1686, las autoridades de Murcia remitieron a las de Orihuela una copia del amojonamiento de 1610 obtenida de su propio archivo, para a la vista del documento poder llegar a un acuerdo.

Pero dado que transcurría el tiempo y por parte de Orihuela no se avanzaba en aras de llegar a un acuerdo común, las autoridades de Murcia remitieron a los de Orihuela una copia del deslinde o amojonamiento de 1441, teniendo como bueno y aceptado por ambas partes, para que la resolución del conflicto se adoptase sobre el deslinde establecido en el amojonamiento de 1441 .

En el documento de 1668 también hemos localizado una expresión significativa sobre el significado de línea derecha o línea recta.

"En 30 del mesmo mes de abril, escrivimos que los mojones estavan en su devida forma y que no abia necesidad de reconoserlos y renovarlos, sino solo lo que por parte de Vd. Hera una persona y otra por la nuestra ya que en su presencia y de los vecinos que se quisieran hallar, se sacaran las lineas retas de mojon a mojon por medio de agrimensores de ambas ciudades" $" 96$

\section{LAS REVISIONES DEL DESLINDE DE 1441. LAS COMISIONES DE REVISIÓN DE MOJONES (1756)}

En 1756 se procedió a una nueva revisión de mojones y no a un nuevo amojonamiento. La comisión de visitadores de 1756 procedió a una exhaustiva revisión de los mojones establecidos en 1441, para aclarar su ubicación, su situación actual, la necesidad de reconstruir algún mojón deteriorado, etc. De ahí que de forma clara en el documento de amojonamiento de 1756 se incluya como inserto, el texto del amojonamiento de $1441^{97}$.

“...encontraron un mojon derruhido que expresaron ser de los Modernos hecho de mortero barro y piedras el que se halla a orilla del Camino que di-

96 AMMU, CAM, 785, no 9, f. 12v. (1668, agosto, 31).

97 A.M.O. D-2497, f. 139r. (1441, septiembre, 21). 
xeron va a Siete Higueras y en tierras de D. Francisco de Alvares de la ciudad de Murcia y a partes de Joseph Vera Jalapaz..."98

\section{CONCLUSIONES}

En 2006 una curiosa noticia de carácter local, llegaba a los medios de comunicación más relevantes de España. Con el titular "San Pedro del Pinatar «invade» Alicante", uno de los medios de comunicación más veteranos y prestigiosos de España, encabezaba una noticia en la que informaba a sus lectores de la actuación del entonces alcalde de Pilar de la Horadada, que sobre la base de un documento del siglo XIX se había anexionado parte de los términos municipales de Pilar de la Horadada de Alicante y San Javier de Murcia. En el caso de Pilar de la Horadada, la noticia tenía una repercusión adicional ya que dicho municipio pertenecía a otra provincia, Alicante y a otra comunidad autónoma, la Comunidad Valenciana ${ }^{99}$. La consecuencia de dicha acción del entonces alcalde de San Pedro del Pinatar, que había actuado con base en un informe previo elaborado por un equipo de investigadores de la Universidad de Murcia, fue el encargo que realizó el entonces alcalde de Pilar de la Horadada a un equipo de investigadores multidisciplinar de la Universidad de Alicante, del que formé parte, para elaborar un informe con el objetivo de rebatir la actuación realizada desde el municipio de San Pedro del Pinatar. A partir de la conclusiones emitidas en dicho informe, la justicia falló a favor de Pilar de la Horadada y por tanto de mantener los mojones históricos en su emplazamiento tradicional.

Lo más destacado de dicho informe y de las consecuencias derivadas del mismo, fue constatar la vigencia jurídica actual de los mojones implantados en el siglo XV, además de poder comprobar en primera persona, la utilidad para la sociedad del oficio de historiador y el valor del registro documental histórico, de las provisiones, privilegios, acuerdos legales, etc., rubricados por las autoridades políticas medievales.

Al mismo tiempo, pude documentar una actuación puntual que contradecía la visión que prevalecía, en líneas generales, sobre las sociedades fronterizas, desde la óptica de la violencia sistémica y el enfrentamiento visceral entre entidades políticas fronterizas. Sin negar estas violencias, tensiones, rivalidades e identidades enfrentadas, los acuerdos de lindes de 1441 y 1462 demuestran una capacidad extraordinaria de consenso y acuerdo político, entre dos municipios fronterizos y su capacidad para ofrecer soluciones a pro-

98 A.M.O. D-2497.

99 "San Pedro del Pinatar «invade» Alicante". ABC, 30 de enero de 2006. 
blemas enquistados en el espacio y en el tiempo y que tenían repercusiones muy negativas para los ciudadanos de ambos municipios y para el desarrollo económico de ambas entidades urbanas.

La organización del espacio y especialmente la delimitación de los lindes fronterizos, acometida en el siglo XV, es consecuencia de un intenso aprovechamiento económico de los recursos naturales, por parte de vecinos de dos localidades fronterizas, lo que es una muestra más de una Centuria expansiva y frente a ello de la necesidad por parte de los dos concejos enfrentados, de dar respuestas políticas a tensiones fronterizas, que provocaban conatos de violencia, enfrentamientos armados, detenciones, confiscación de bienes, etc., y generaban una fuerte incertidumbre entre los ciudadanos implicados en su capacidad para la explotación de los recursos económicos en las rayas fronterizas.

La conclusión final es la vitalidad de los espacios fronterizos, entendidos como territorios dotados de un dinamismo político, económico y social que generaba sinergias expansivas. El análisis de los espacios de frontera, por ello, debe ir más allá del análisis de los conflictos armados y debe analizar también acciones y respuestas novedosas por parte los individuos que vivían en la raya fronteriza, sobre cuestiones que surgían con la máxima cruzada y virulencia y que requerían de respuestas alternativas al choque de metales. La capacidad de encontrar en la acción política, en el pacto y en el consenso soluciones a conflictos que con facilitad podían derivar en enfrentamientos armados muestran una vez más la madurez institucional de las sociedades de frontera y de sus instituciones. 